\title{
Article \\ STO vs. ICO: A Theory of Token Issues under Moral Hazard and Demand Uncertainty
}

\author{
Anton Miglo
}

check for updates

Citation: Miglo, Anton. 2021. STO vs. ICO: A Theory of Token Issues under Moral Hazard and Demand Uncertainty. Journal of Risk and Financial Management 14: 232. https://doi.org/10.3390/ jrfm14060232

Academic Editor: Paweł Ziemba

Received: 21 April 2021

Accepted: 14 May 2021

Published: 21 May 2021

Publisher's Note: MDPI stays neutral with regard to jurisdictional claims in published maps and institutional affiliations.

Copyright: (c) 2021 by the authors. Licensee MDPI, Basel, Switzerland. This article is an open access article distributed under the terms and conditions of the Creative Commons Attribution (CC BY) license (https:/ / creativecommons.org/licenses/by/ $4.0 /)$.
Salford Business School, University of Salford, Salford M5 4WT, UK; a.miglo@salford.ac.uk

\begin{abstract}
This paper considers a financing problem for an innovative firm that is launching a webbased platform. The entrepreneur, on one hand, faces a large degree of demand uncertainty on his product and on the other hand has to deal with incentive problems of professional blockchain participants who contribute to the development and sales of the product. We argue that hybrid tokens can be a better option for the firm compared to straight utility tokens or security tokens because they help the firm better deal with both the moral hazard problems (via profit sharing incentives) and demand uncertainty (they help the firm learn the market demand for the product). This finding is consistent with some recent evidence. The paper also generates new predictions regarding the effect of different variables on the choice of financing method that have not yet been tested.
\end{abstract}

Keywords: entrepreneurial finance; blockchain; initial coin offering; security token offering; moral hazard; demand uncertainty; FinTech

JEL Classification: D82; G32; L11; L26; M13

\section{Introduction}

Innovative companies account for a significant share of the global market for human capital but they are often constrained in their growth potential as they have difficulty accessing capital markets (Hall 2009; Wilson 2015). For example, an absence of credit records or any successful financial history usually creates a barrier for a good bank loan. Even if a bank is willing to consider a firm's business plan, the assets of innovative companies are largely intangible, which creates difficulties for banks to design a high risk loan contract, for example, using collateral. An increase in interest rate is often not a good way forward for banks since it may create an incentive for excessive risk taking by firms (in the spirit of the credit rationing literature (Stiglitz and Weiss 1981)). Because of this, innovative firms often play a pivotal role in new financing tools' development (financial innovations). This includes private equity, business incubators, venture capital finance, project finance, angel finance, seed accelerators and more recently crowdfunding. Token issues are the newest innovation in this area.

The two most popular types of token issues are initial coin offerings (ICOs) and security token offerings (STOs). The ICO phenomenon dates back to 2013. Between 2013 and 2017, the number and funding of projects grew exponentially, with over $\$ 20$ billion raised by December 2018 (Coinschedule 2018). In a typical ICO, an entrepreneur raises capital by selling utility tokens, which give their owners the right to use the company's product or service once it is developed. For many innovative companies it represents an attractive idea since it not only helps them with raising funds for their projects but it also often helps them with building their future customer base. In 2017, fintech companies started to use security token offerings (STOs) to finance their projects. In security token offerings (STOs), ${ }^{1}$ companies sell tokenized traditional financial instruments, such as, for example, equity where tokenholders receive rights to a firm's future profits. ${ }^{2}$ In 2017 , five STOs were conducted, while in 2019 there were 55 STOs. ${ }^{3}$ The 6 th ICO/STO report (2020) identified 380 token offerings that raised $\$ 4.1$ billion. 
ICO and STO research is quickly growing. Most papers are focused on ICOs. Theoretical papers on ICOs include, among others, Canidio (2018); Catalini and Gans (2018); Bakos and Halaburda (2018); Cong et al. (2018); Li and Mann (2018); Lee and Parlour (2020); Chod and Lyandres (2019); Garratt and van Oordt (2019); Holden and Malani (2019); Miglo (2020d). ${ }^{4}$ Research on STOs is in its early stages and it includes Gan et al. (2020) and several empirical papers (e.g., Adhami et al. 2018; Ante and Fiedler 2019; Lambert et al. 2020). In this article, we focus on the analysis of economic ideas behind issuing hybrid tokens that have features of both ICOs and STOs. ${ }^{5}$ For many entrepreneurs, this issue seems to be very important. ${ }^{6}$

Our model builds on the following observations. First, both ICOs and STOs are characterized by environments with high uncertainty. Many campaigns fail or turn out to be low quality or even fraud in some cases. ${ }^{7}$ A firm's success in these innovative areas crucially depends on the incentives and efforts of not only the firm itself but on the many participants involved. These efforts include validating transactions (often referred to as "mining") on a blockchain ledger that involves different types of operational costs (e.g., labour, computers, energy etc.), as well as the project development costs such as marketing and technology development. In fact, the very nature of fintech platforms is related to the concept of "no middle men" 8 (such as banks for example) and, respectively, the technology used by these platforms is based on the effort and trust existing between the platform participants (sometimes they are called a distributed ledger, emphasizing that the efforts and costs are distributed among many participants and the platform performance depends on these efforts and costs). ${ }^{9}$ An interesting case is Filecoin, which set up a network to allow peer-topeer storage space sharing. Its success depends on the actions and strategies of so-called miners who are expected to be active participants of this platform. Token design issued by the platform may affect the incentives of parties involved. In the case of Filecoin, miners purchased tokens during the pre-sale. ${ }^{10}$ Second, tokens serve as a learning tool for entrepreneurs regarding market demand. By observing the demand for tokens during the initial sale of tokens or by observing the token market price, the entrepreneur can learn "crowd wisdom" regarding the platform and its products. Finally, tokens have secondary markets (see, for example, the interview with BlockState CEO Paul Claudius) ${ }^{11}$ unlike, for example, venture capital investments. This feature of tokens makes it also different from crowdfunding which typically does not have a secondary market for investments made by funders and from, for example, traditional venture capital financing. ${ }^{12}$

In our model an entrepreneur with an innovative idea considers launching a webbased platform. The demand for the product is highly uncertain so the entrepreneur can make production decisions without learning demand or he can issue tokens prior to making production decisions. The success of the platform also crucially depends on the effort provided by the entrepreneurs and blockchain participants (miners) during the development stage. Utility tokens give the right to purchase a product or service on the platform while security tokens give a right on firm profit. The "wisdom of the crowd" aspect of a platform kicks in when the firm is facing demand uncertainty. Without utility tokens, production (and respectively pricing) decisions of the firm are not optimal. Usage of utility tokens helps the firm to learn the demand and improve its decision-making including production (pricing) decisions. However the shortcoming of utility tokens is that they do not provide much incentive for miners to develop the product. On the other hand security tokens do not provide a flexible tool for learning market demand. We then analyze the trade-off between security tokens and utility tokens for the entrepreneur. We show, for example, that the utility tokens will be preferred if the degree of uncertainty regarding market demand is higher (it increases the learning value of utility tokens).

Next we consider other financing strategies for the firm that include a mixture of features of both utility tokens and security tokens and argue that these strategies can be more beneficial for the firm. We demonstrate that this type of strategy dominate regular utility tokens or security tokens. Learning opportunities, in terms of demand for this kind of strategy, still exist, which makes it similar to traditional utility tokens. In contrast to 
these tokens, they also do a better job of incentivizing miners during the development stage. Finally, if the token issue fees are taken into account then issuing hybrid tokens (utility tokens with profit rights) is a better option for the firm compared to other "mixed" strategies since the firm can avoid multiple fees and other costs related if it conducts multiple issues of different tokens.

Our model provides several predictions most of which have not yet been tested. Interestingly though, one of our main predictions namely that utility tokens with profit rights can dominate utility tokens without this right is consistent with recent empirical evidence. In a subsample of 253 campaigns, Adhami et al. (2018) document higher returns when tokens allow contributors to access a specific service including profit rights. Our results also provide several implications for policymakers and practitioners. First, it explains factors that should be taken into account by managers designing optimal token design for their firms. Secondly our results can help different platforms hosting ICOs and STOs compare the suitability of the different types of tokens with a variety of business factors, which ultimately can help platforms deal with different issuers and minimize risks (maximize quality).

KuCoin CEO Michael Gan explains that the advantage of why his business is doing relatively well compared to its competitors and why its tokens have an active and growing market is that their tokens have both utility value and profit sharing rights. It helps on one hand to provide all services to customers but also ensures financial incentives even when markets seems to be bearish. "... As the native token of KuCoin, KCS holders now can enjoy trading fee discount and daily KCS bonus on our platform. ... KCS also has gradually been accepted by increasing number of industry partners. You can now use KCS to get a loan on ETHLend, transfer KCS to your friends on Adamant Messenger, pay private expenses with KCS through Aave pay. More use cases will be unveiled this quarter." In many articles KCS is named one of the best dividend paying tokens so it has aspects of both utility tokens and security tokens. ${ }^{13}$ There are many other examples of cryptobusinesses that use similar ideas including Binance, Medpath, XWIN, Elephant, Props, Treecoin, XOV and so forth.

The rest of the paper is organized as follows: Section 2 provides a literature review. Section 3 describes the basic model and some preliminary results. Section 4 provides an analysis for the model with moral hazard and demand uncertainty. Section 5 analyzes the role of utility tokens with profit sharing rights (hybrid tokens). Section 6 discusses the consistency of the model's predictions with observed empirical evidence. Section 7 discusses the model's robustness and its potential extensions and Section 8 is a conclusion to the study.

\section{Literature Review}

ICO and STO research is quickly growing. Chen et al. (2021); Bellavitis et al. (2020); Miglo (2021); Howell et al. (2018); Adhami et al. (2018) provide good reviews of the literature in this field. Several topics are important and are closely related to the present paper.

1. General research directions in fintech and token issues. Adhami et al. (2018) mentioned that one of the most important questions in ICO research is to better understand whether ICOs have indeed the potential to increase the efficiency of new business financing or do they just represent a new Ponzi scheme. Chen et al. (2021) mentioned that gametheoretic approach is an important direction to study the benefits of blockchain-related issues. Reference Miglo (2021) mentioned that STOs and other type of token issues are less analyzed than ICOs.

The present paper is based on the above ideas. We analyze the efficiency aspects of token issues for example, market learning. We use a game-theoretic approach as our main tool to build a model to analyze the trade-off between learning market demand and moral hazard issues. Finally our main focus in this paper is on STOs and further on hybrid token that have not been extensively analyzed in the existing literature. 
2. Moral hazard issues. Garratt and van Oordt (2019) studied the effect of entrepreneurial moral hazard on ICO outcomes and find conditions for when an ICO is a better choice than traditional debt or venture capital. Chod et al. (2019) shows that decentralized governance associated with tokenization can further mitigate entrepreneurial effort underprovision by eliminating a potential holdup of users. Canidio (2018) argues that the entrepreneur's effort depends on the discount factor and the elasticity of a product's demand. Gan et al. (2020) compare utility tokens and equity tokens. In their paper, the moral hazard exists in the form of cash withdrawal incentive (similar to Strausz 2017). Gryglewicz et al. (2020) show that token financing is preferred to equity financing, unless the platform expects strong cash flows, has large financing needs, or faces severe agency conflicts. In our paper we study moral hazard based on the cost of entrepreneurial effort (in the spirit of Jensen and Meckling 1976). Compared to these papers, we also study the incentives of other blockchain participants related to moral hazard problems (in the spirit of moral hazard in teams idea (Alchian and Demsetz 1972; Holmström 1982). In a recent study, Garicano et al. (2017) suggested that an important question is to understand if moral hazard in teams and information problems can be addressed simultaneously. ${ }^{14}$

Compared to the papers mentioned above, our main focus is on hybrid tokens.

3. Learning market demand. In Catalini and Gans (2018) an ICO allows an entrepreneur to generate buyer competition for the token, which, in turn, reveals consumer value without the entrepreneurs having to know, ex ante, consumer willingness to pay. In our paper, on the other hand, tokens can help entrepreneur learn market demand in each period by observing the token price on the secondary market. In addition, we also study hybrid tokens and their role in learning market demand. Note that this idea is also related to crowdfunding literature. Under demand uncertainty, crowdfunding helps firms learn market demand for their products and services (Strausz (2017); Chemla and Tinn (2019); Schwienbacher (2018); Catalini and Gans (2018); Ellman and Hurkens (2017)). In contrast to crowdfunding (in particular to reward-based crowdfunding), firms that use token issues can learn the demand for tokens issued by the firm by observing the dynamics of secondary market for tokens and so forth.

In fact, market uncertainty related primarily to increasing market sizes and fast growing amounts of market data is often considered as one of the main triggers for the development of fintech (often considered as a new "revolutionary" area of finance) that includes many innovative tools and technologies including, for example, big data analytics (see e.g., Das 2019). An important line of research analyzes the innovative methods and models of learning in high uncertainty environment including fuzzy methods. See, for example, Jankowski et al. (2016) and Watróbski et al. (2016).

In our paper tokens can help entrepreneur learn market demand by observing the token price. As was mentioned previously, unlike reward-based crowdfunding, tokens have secondary market. This helps to implement learning for a longer period of time while under crowdfunding learning is limited to initial stage of venture development.

4. Interaction of production and financing decisions. Our paper also contributes to the financing and capital structure literature that connects firm financing decisions and production decisions (for a recent review see, for example, Li and Wang 2019). See, for example, Brander and Lewis (1986); Bolton and Scharfstein (1990); Williams (1995). This literature suggested that the choice of financing strategy does not only affect the firm's financial benefits and costs but also strongly affects its production strategy. Brander and Lewis (1986), for example, argued that a high level of debt financing can push the firm to adopt a very aggressive competitive strategy and its production strategy. Token issues fall naturally in this line of research since by definition an ICO, for example, does not only represent a financing tool for a firm but also is an important part of its sales and respectively a part of its marketing strategy and so forth.

5. Financing strategy and monetary economics. As was previously mentioned token issues are an important part of fintech that represents a revolutionary development in the finance industry. A part of it is a changing role of financial manager. Between the 1950s and 1990s 
the works of several leading financial researchers (Modigliani and Miller 1958; Jensen and Meckling 1976; Myers and Majluf 1984, etc.) led to the development of many important concepts in the area of firm financing including asymmetric information, moral hazard, debt tax shield, bankruptcy costs and so forth. The level of understanding of the importance of financing strategy reached new levels among financial managers (see e.g., a survey by Graham and Harvey 2001). A part of this new vision was mentioned previously the idea of connectedness between firm's financing decisions and production decisions (e.g., Brander and Lewis 1986). The area of financing is currently making a new step. This is closely related to the fintech development in that a firm financing strategy becomes closely related to monetary economics. Tokens are in many ways similar to traditional fiat money since they can be used to buy firm's products and services. Financial managers dealing with tokens need to understand such concepts as token circulation, their exchange rate (i.e., their secondary market price), token velocity and so forth, that requires the knowledge of ideas from monetary economics. Our paper contributes to these development by suggesting a model with all three mentioned previously aspects of firms strategy including financing operations, production decisions and monetary aspects of firm's policy.

\section{The Model Description and Some Preliminaries}

An innovative firm has monopoly power over its idea of creating a website platform selling a product/service for two periods. The platform's quality depends on the effort provided by the entrepreneur $\left(e_{1}\right)$ and the blockchain participants (we call them miners for brevity) $\left(e_{2}\right)$. The cost of effort is $\frac{e_{j}^{2}}{2}, j=1,2 .{ }^{15}$ During the operational stages of the platform, the demand for product in period $n$ is expected to be driven by the following demand function: $q_{n}=v_{n}-p_{n}$, where $p_{n}$ is the price and $q_{n}$ is the quantity demanded in period $n, n=1,2$. For convenience we let $v_{1} \equiv v$ and $s=v_{2} / v$. $s$ is the demand scale factor in period 2 compared to period $1 . v$ can be either high $\left(v_{h}\right)$ or low $\left(v_{l}\right)$. The probability of high demand is $\mu$. Let $\Pi_{n}$ be the firm's operational profit in period $n$. Respectively $Q\left(e_{1}, e_{2}\right)\left(\Pi_{1}+\Pi_{2}\right)$ is the value of the firm's earnings where $Q\left(e_{1}, e_{2}\right)$ is a factor that reflects the platform's quality. We assume

$$
Q\left(e_{1}, e_{2}\right)=e_{1}+e_{2}
$$

The discount factor is not modelled in the basic model but we discuss it in the multi-period extension in Section 7. The calculations of $\Pi_{n}$ as well as the way the firm's earnings will be distributed depend on the firm's financing strategy. To finance the development of the product the firm can sell tokens. Tokens may vary in design. They can be utility tokens which give the tokenholder the right to purchase the product on the platform. They can also be security tokens which give tokenholders profit sharing rights. ${ }^{16}$ The firm is owned by an entrepreneur who is risk-neutral and who maximizes the present value of his expected earnings minus the expected cost of effort.

Utility tokens. Initially, that is, before the platform is launched, the firm sells tokens to miners for the price $p_{0} \cdot{ }^{17}$ The total number of tokens is normalized to unity without loss of generality. As we will see, the relative fractions of tokens owned by the entrepreneur, miners and public are important. After the first issue of tokens is sold, the entrepreneur and the miners provide their efforts. Miners then trade tokens on the secondary market. The miner's profit equals the difference between the value of tokens sold on the secondary market and the cost of effort provided. After that the platform is launched. The entrepreneur determines the level of production in period 1. In period 2, the entrepreneur sells tokens received from selling the product in period 1. After that he determines the level of production in period 2. At the end of each period the produced items are exchanged for tokens ( $T_{n}$ is the product's price in tokens).

Security tokens. The firm selects the fraction of equity $\alpha$ that will belong to security token holders and sells them during the STO to miners. After that the entrepreneur and miners select their production efforts. The platform is launched. In each period, the firm 
produces its products/services and sells them to the public. The firm's earnings are distributed pro-rata according to the number of tokens owned by each tokenholder.

First consider the symmetric information scenarios without moral hazard problems for the different types of tokens. We assume that $v$ is given and the quality of platform $Q$ is also given and equals 1 for simplicity and it does not depend on any efforts made by the entrepreneur or miners.

\subsection{Utility Tokens}

The timing of events is presented in Figure 1.

\begin{tabular}{|c|c|c|}
\hline$t=0$ & $t=1$ & $t=2$ \\
\hline $\begin{array}{l}\text { Firm sells tokens to } \\
\text { miners }\end{array}$ & $\begin{array}{l}\text { Miners sell their tokens on } \\
\text { the secondary market for } \\
\text { the price } p_{1}\end{array}$ & $\begin{array}{l}\text { The entrepreneur sells tokens on } \\
\text { the secondary market for the price } p_{2}\end{array}$ \\
\hline \multirow[t]{3}{*}{$p_{0}$ is determined } & The platform is launched & The firm determines $q_{2}$ \\
\hline & The firm determines $q_{1}$ & $\begin{array}{l}\text { Tokens are exchanged for products } \\
\text { for the price } T_{2} \text { per item (in tokens) }\end{array}$ \\
\hline & $\begin{array}{l}\text { Products are sold to } \\
\text { the public for tokens } \\
\text { for the price } T_{1} \text { per item } \\
\text { (in tokens) }\end{array}$ & \\
\hline
\end{tabular}

Figure 1. The sequence of events for utility tokens.

We begin the solution by working backwards. In period 2, the entrepreneur sells tokens for the price $p_{2}$. After tokens are sold, the firm determines $q_{2}$. Tokenholders then use their tokens to buy products.

Equilibrium is determined by the following conditions: (1) when selecting the number of tokens, the firm resells all tokens $X_{2}$ received from selling products in period 1 (as with the initial number of issued tokens the change in the nominal number of circulated tokens is irrelevant); (2) when selecting $q_{2}$, the firm maximizes the value of tokens received from sales, which equals $q_{2} T_{2} p_{2}$ (production-incentive constraint) that is equivalent to the entrepreneur's profit in period $2{ }_{1}^{18}$ (3) demand equilibrium:

$$
q_{2}=s v-P_{2},
$$

where $P_{2}$ is the cost of the product for the public:

$$
P_{2}=T_{2} p_{2}
$$

For example, if the product price is 2 tokens/item and the market price of the token is $\$ 3 /$ token (note that this also equals to the total market value of tokens since the total number of tokens is normalized to unity) then the total real cost of the product for the public equals $2 * 3=6 \$$. Taking into account (2) and (3), the entrepreneur's objective function can be written as $\left(s v-q_{2}\right) q_{2}$. The optimal $q_{2}$ equals

$$
q_{2}=\frac{s v}{2}
$$

and the entrepreneur's profit equals:

$$
\frac{s^{2} v^{2}}{4} .
$$

From (2) and (4) we have (no-arbitrage condition): ${ }^{19}$

$$
P_{2}=\frac{s v}{2}
$$


(3) implies:

$$
\frac{s v}{2}=T_{2} p_{2}
$$

Token market equilibrium (supply equals demand) is described by the following condition: ${ }^{20}$

$$
X_{2}=q_{2} T_{2}=1 .
$$

This implies:

$$
\begin{gathered}
T_{2}=\frac{2}{s v} \\
p_{2}=\Pi_{2}=\frac{s^{2} v^{2}}{4} .
\end{gathered}
$$

Firm profit during period 2 equals $\frac{s^{2} v^{2}}{4}$.

At the beginning of period 1, miners sell their tokens on the secondary market for the value:

$$
p_{1}=\frac{v^{2}}{4} \text {. }
$$

When selling tokens in period 0 , the entrepreneur's total expected profit is:

$$
p_{0}+\frac{s^{2} v^{2}}{4}
$$

under the condition that miners' profits covers their investment costs

$$
\frac{v^{2}}{4} \geq p_{0}
$$

We assume that there is a large number of miners so they agree to invest an amount equal to the present value of their future profits. The entrepreneur's total profit equals

$$
\Pi=\frac{s^{2} v^{2}}{4}+\frac{v^{2}}{4}=\frac{v^{2}\left(1+s^{2}\right)}{4} .
$$

\subsection{Security Tokens}

The timing of events is presented in Figure 2.

$\begin{aligned} & \text { Firm selects } \alpha \text { and } \\ & \text { sells tokens } \\ & \text { to miners }\end{aligned}$
$\begin{aligned} & \text { Miners sell their tokens on } \\ & \text { the secondary market for } \\ & \text { the price } p_{1}\end{aligned}$
$\begin{aligned} & \text { The platform is launched } \\ & \text { The firm determines } q_{1}\end{aligned}$
$\begin{aligned} & \text { Products are sold } \\ & \text { to the public }\end{aligned}$

Figure 2. The sequence of events for security tokens.

Consider the operational stage. In period 2 there are $q_{2}$ items produced. The entrepreneur's objective function can be written as $C_{2}=(1-\alpha)\left(s v-q_{2}\right) q_{2}$. The optimal $q$ equals

$$
q_{2}=\frac{s v}{2}
$$


and the entrepreneur's profit equals:

$$
\frac{(1-\alpha) s^{2} v^{2}}{4}
$$

In period 1 it equals $\frac{(1-\alpha) v^{2}}{4}$. The total value of the entrepreneur's profits equals

$$
\frac{(1-\alpha) s^{2} v^{2}}{4}+\frac{(1-\alpha) v^{2}}{4} .
$$

The miners' profit equals:

$$
\frac{\alpha s^{2} v^{2}}{4}+\frac{\alpha v^{2}}{4}
$$

When choosing $\alpha$, the entrepreneur maximizes:

$$
p_{0}+\frac{(1-\alpha) s^{2} v^{2}}{4}+\frac{(1-\alpha) v^{2}}{4}
$$

under the condition that the miners' profit covers their investment cost

$$
p_{0}=\frac{\alpha s^{2} v^{2}}{4}+\frac{\alpha v^{2}}{4} .
$$

The entrepreneur's total profit equals then

$$
\Pi=\frac{s^{2} v^{2}}{4}+\frac{v^{2}}{4}=\frac{v^{2}\left(1+s^{2}\right)}{4} .
$$

Lemma 1. Without moral hazard and demand uncertainty, the firm is indifferent between the different types of tokens.

Proof. Follows from the comparison of (7) and (8).

This result is not surprising given that, in the absence of any financial market imperfections, every type of financing should have the same result (similar to the Modigliani-Miller proposition Modigliani and Miller (1958)).

\section{Product Development, Market Uncertainty and Incentives}

In this section, we analyze the role of moral hazard and market uncertainty in the firm's choice of tokens. The entrepreneur and miners provide efforts in the development stage of the platform that affect its quality. The token design affects the incentives of all the parties involved. The market demand for platform products is also uncertain. The token design affects the platform ability to learn information about market demand before the entrepreneur makes his production decisions.

The timing of events for utility tokens is present in Figure 3.

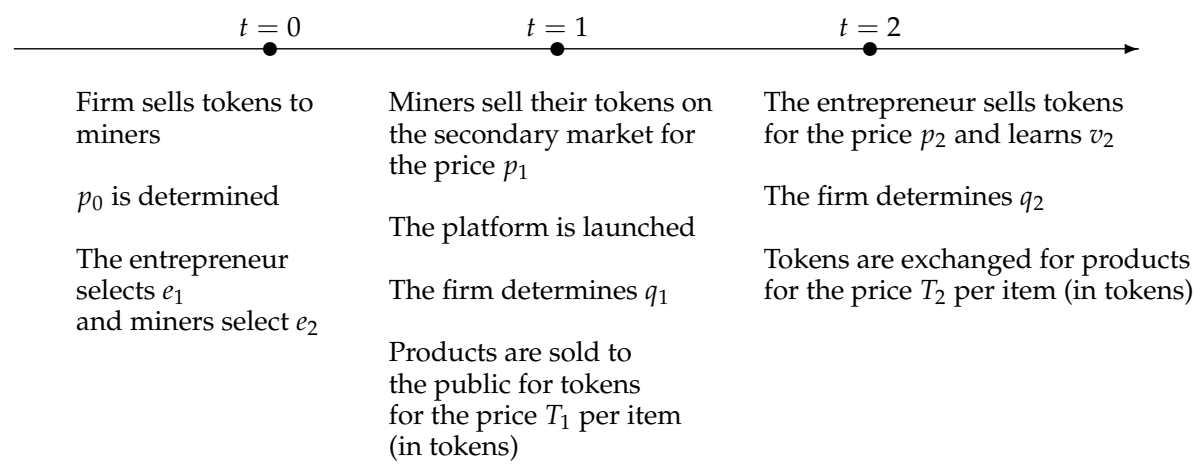

Figure 3. The sequence of events with moral hazard and market uncertainty for utility tokens. 
The timing of events for security tokens is present in Figure 4.

\begin{tabular}{|c|c|c|}
\hline$t=0$ & $t=1$ & $t=n$ \\
\hline $\begin{array}{l}\text { Firm selects } \alpha \\
\text { and sells tokens } \\
\text { to miners }\end{array}$ & $\begin{array}{l}\text { Miners sell their tokens on } \\
\text { the secondary market for } \\
\text { the price } p_{1}\end{array}$ & $\begin{array}{l}\text { The firm determines } q_{2} \\
\text { Products are sold to public }\end{array}$ \\
\hline$p_{0}$ is determined & The platform is launched & \\
\hline $\begin{array}{l}\text { The entrepreneur } \\
\text { selects } e_{1} \\
\text { and miners select } e_{2}\end{array}$ & $\begin{array}{l}\text { The firm determines } q_{1} \\
\text { Products are sold to } \\
\text { the public }\end{array}$ & \\
\hline
\end{tabular}

Figure 4. The sequence of events with moral hazard and market uncertainty for security tokens.

We will proceed in three steps. First, we will consider the case with moral hazard without market uncertainty. Next, we will consider the implications of market uncertainty and finally we will consider them together.

\subsection{Moral Hazard}

Lemma 2. Under moral hazard, the entrepreneur's profit when the firm issues security tokens is higher than with utility tokens.

Proof. See Appendix A.1.

Below is the outline of the proof. Under utility tokens we show that an optimal level of efforts by the entrepreneur and miners are respectively $e_{1}=\frac{v^{2} s^{2}}{4}$ and $e_{2}=\frac{v^{2}}{4}$ and the firm's value equals

$$
\Pi=\frac{\left(s^{4}+4 s^{2}+1\right) v^{4}}{32} .
$$

Under security tokens the level of efforts are respectively

$$
e_{1}=\frac{\left(1+s^{2}\right)(1-\alpha) v^{2}}{4}
$$

and

$$
e_{2}=\frac{\left(1+s^{2}\right) \alpha v^{2}}{4} .
$$

Note that the effort of each party increases with the fraction of profits offered to each party (in the spirit of Jensen and Meckling 1976). The firm's profit equals

$$
\Pi=\frac{3\left(1+s^{2}\right)^{2} v^{4}}{64} .
$$

Lemma 2 follows from the comparison of (9) and (12). Indeed the difference between them can be written as $\frac{3\left(1+s^{2}\right)^{2} v^{4}}{64}-\frac{\left(s^{4}+4 s^{2}+1\right) v^{4}}{32}=\frac{\left(s^{2}-1\right)^{2} v^{4}}{64(1+\delta)^{4}}>0$.

The idea behind Lemma 2 is that miners are better incentivized with security tokens. Miners receive part of the firm's profit and if this part is sufficiently high they provide a higher level of effort than with utility tokens. The entrepreneur's effort is reduced but not by much since the entrepreneur keeps a large fraction of equity in any case for a long period of time in the company. Most importantly when maximizing his objective function initially, the entrepreneur has flexibility in terms of selecting the optimal fraction of equity for selling to miners by taking into account the cost of the miners' efforts and his own cost. As one can see from (10) and (11), the entrepreneur and the miner's profits depend on the fraction of profits offered to security token holders. With a proper selection of the fraction of profit offered to security token holders, the firm can provide a good combination of 
incentives in the case of security token issues. Under utility tokens, the entrepreneur does not have much flexibility in managing the levels of efforts since utility tokens do not give their holders a long-term fraction of the firm's equity so the level of incentives that can be induced with utility tokens is smaller than it is with security tokens.

\subsection{Demand Uncertainty}

Here, we assume that in each period the demand for the product offered by the platform is either $v_{h}$ with probability $\mu$ or $v_{l}$. Issuing utility tokens helps the entrepreneur learn the demand and helps with production decisions.

Lemma 3. Under demand uncertainty, the entrepreneur's profit when the firm issues utility tokens is higher than it is when the firm issues security tokens.

Proof. See Appendix A.2.

As shown in Appendix A.2, the firm's profit under utility tokens equals

$$
\frac{\left(1+s^{2}\right)\left(\mu v_{h}^{2}+(1-\mu) v_{l}^{2}\right)}{4}
$$

and under security tokens it equals

$$
\frac{\left(1+s^{2}\right)\left(\mu v_{h}+(1-\mu) v_{l}\right)^{2}}{4} .
$$

Lemma 3 follows from the comparison of (13) and (14). Indeed the difference between them can be written as $\frac{\left(1+s^{2}\right)\left(\mu v_{h}^{2}+(1-\mu) v_{l}^{2}\right)}{4}-\frac{\left(1+s^{2}\right)\left(\mu v_{h}+(1-\mu) v_{l}\right)^{2}}{4}=\frac{\left(1+s^{2}\right) \mu(1-\mu)\left(v_{h}-v_{l}\right)^{2}}{4}>0$.

The idea behind Lemma 3 is that the firm learns the market demand when selling utility tokens, which were collected in the previous period, on the secondary market at the beginning of each period. This is consistent with the idea of learning via "crowd wisdom".

\subsection{Moral Hazard and Demand Uncertainty}

In this section,we analyze token design when market uncertainty and moral hazard are both present.

Proposition 1. Under moral hazard and demand uncertainty, the firm's profit if it issues utility tokens equals

$$
\frac{\left(s^{4}+4 s^{2}+1\right)\left(\mu v_{h}^{2}+(1-\mu) v_{l}^{2}\right)^{2}}{32} .
$$

If the firm issues security tokens, its profit equals

$$
\frac{3\left(1+s^{2}\right)^{2}\left(\mu v_{h}+(1-\mu) v_{l}\right)^{4}}{64} .
$$

Proof. See Appendix A.3.

Naturally, profit in either case increases with the expected demand $\left(s, v_{h}, v_{l}\right.$ and $\left.\mu\right)$.

Proposition 2. The likelihood of selecting utility tokens increases (respectively the likelihood of selecting security tokens decreases) when $\mu$ increases from 0 to $\frac{v_{l}}{v_{l}+v_{h}}$ and decreases when $\mu$ increases from $\frac{v_{l}}{v_{l}+v_{h}}$ to 1 ; when $s$ decreases and $s<1$ and when sincreases and $s>1$.

Proof. We need to compare (15) and (16). The latter is greater when

$$
\frac{3\left(1+s^{2}\right)^{2}\left(\mu v_{h}+(1-\mu) v_{l}\right)^{4}}{64}>\frac{\left(s^{4}+4 s^{2}+1\right)\left(\mu v_{h}^{2}+(1-\mu) v_{l}^{2}\right)^{2}}{32}
$$


or

$$
\frac{3\left(1+s^{2}\right)^{2}}{s^{4}+4 s^{2}+1}>\frac{2\left(\mu v_{h}^{2}+(1-\mu) v_{l}^{2}\right)^{2}}{\left(\mu v_{h}+(1-\mu) v_{l}\right)^{4}} .
$$

The derivative of right-hand side (RHS; LHS will be used for left-hand side) of (17) in $\mu$ equals:

$$
\frac{\left(v_{h}-v_{l}\right)\left(\mu v_{h}+(1-\mu) v_{l}\right)\left(\frac{v_{l}}{v_{l}+v_{h}}-\mu\right)}{\left(\mu v_{h}^{2}+(1-\mu) v_{l}^{2}\right)^{2}}
$$

which proves the first part of the proposition. Indeed, the sign of (18) is determined by the sign of $\frac{v_{l}}{v_{l}+v_{h}}-\mu$. It is positive when $\mu<\frac{v_{l}}{v_{l}+v_{h}}$ and is negative otherwise. The derivative of the LHS of (17) in $s$ equals $\frac{3 s\left(1+s^{2}\right)(s-1)\left(s^{3}+2 s+1\right)}{\left(s^{4}+4 s^{2}+1\right)^{2}}$, which proves the second part.

Proposition 2 has an interesting interpretation. Point 1 is related to the degree of market uncertainty and the amount of information that the entrepreneur can receive when learning the market demand with tokens. Indeed if $\mu=0$ or 1 the amount of information is zero since the demand is deterministic. The same holds if $\mu$ is either very small or very large because there is a large chance that the demand is either very high or low. However when $\mu$ is in the middle the degree of uncertainty is highest since the demand can go either way. Point 2 implies that security tokens are more sensitive to the demand scale factor. If it is low then the effect of security tokens as an incentive device is diminished and vice versa.

The next section shows that if the firm is able to issue tokens with profit rights it can improve its overall outcome.

\section{Utility Tokens with Profit Rights}

Suppose that the firm can issue utility tokens with profit rights (hybrid tokens). This type of tokens represents a unique combination of ideas from both economics and finance. Indeed on one hand, since it can be used to buy firm products or services, it has a lot in common with traditional money. On the other hand, the token holders can also count on future payment/dividends that makes them similar to traditional financial assets. That is why there are many possible ways to theoretically model this type of token. In the spirit of our basic model we continue to assume that the demand for the firm product during stage 2 is $q=s v-p$ and during stage 1 it is $q=v-p$ and that the token velocity is one year. ${ }^{21}$ We provide a detailed discussion of different assumptions as well as alternative ways of modelling in Section 7.9.22

When a firm issues hybrid tokens, the firm selects the fraction of firm's operational profit $\alpha$ that will be paid to tokenholders as a bonus/dividend and sells tokens to miners. ${ }^{23}$ After that, the entrepreneur and miners provide their efforts. Miners sell their tokens on the secondary market. The platform is launched. At the beginning of each period $n, n=1,2$, the firm sells tokens to the public. Then the firm determines the level of production $q_{n}$. Produced items are then exchanged for tokens. The firm pays bonuses $b_{n}$ to tokenholders.

\begin{tabular}{|c|c|c|}
\hline$t=0$ & $t=1$ & $t=2$ \\
\hline $\begin{array}{l}\text { Firm selects } \alpha \text { and } \\
\text { sells tokens to miners }\end{array}$ & $\begin{array}{l}\text { Miners sell their tokens on } \\
\text { the secondary market for } \\
\text { the price } p_{1}\end{array}$ & $\begin{array}{l}\text { The entrepreneur sells tokens } \\
\text { for the price } p_{2} \text { and learns } v_{2}\end{array}$ \\
\hline$p_{0}$ is determined & The platform is launched & dividends $d_{2}$ are paid \\
\hline $\begin{array}{l}\text { The entrepreneur } \\
\text { selects } e_{1}\end{array}$ & The firm determines $q_{1}$ & The firm determines $q_{2}$ \\
\hline and miners select $e_{2}$ & $\begin{array}{l}\text { Products are sold to } \\
\text { the public for tokens } \\
\text { for the price } T_{1} \text { per item } \\
\text { (in tokens) }\end{array}$ & $\begin{array}{l}\text { Tokens are exchanged for products } \\
\text { for the price } T_{2} \text { per item (in tokens) }\end{array}$ \\
\hline
\end{tabular}

The timing of events is present in Figure 5.

Figure 5. The sequence of events with moral hazard and market uncertainty for utility tokens with profit rights. 
Lemma 4. Without moral hazard and when the demand is known, the entrepreneur's profit equals $\frac{v^{2}\left(s^{2}+1\right)}{4}$.

Proof. See Appendix A.4.

This result is not surprising since without market imperfections, the firm's profit is the same as it is with utility tokens or security tokens (see Lemma 1).

Proposition 3. (1) If $s \geq 1$ then under moral hazard and demand uncertainty, the entrepreneur's profit equals:

$$
\frac{3\left(1+s^{2}\right)^{2}\left(\mu v_{h}^{2}+(1-\mu) v_{l}^{2}\right)^{2}}{64}
$$

(2) if $s<1$, the entrepreneur's profit equals $\frac{\left(s^{4}+4 s^{2}+1\right)\left(\mu v_{h}^{2}+(1-\mu) v_{l}^{2}\right)^{2}}{32}$.

Proof. See Appendix A.5.

The amount of earnings is positively correlated with $v_{h}, v_{l}, s$ and $\mu$. For the case $s<1$, as shown in Appendix A.3, optimal $\alpha=0$, which means the issue is equivalent to an ICO.

Proposition 4. When s is sufficiently large, the entrepreneur's earnings in case the firm issues utility tokens with profit rights are higher than they are under security tokens or utility tokens without profit rights.

Proof. As follows from Proposition 3, for the case $s \geq 1$, we need to compare (15), (16) and (19). First note that (19) is greater than (16). Indeed the difference between them can be written as

$$
\frac{3\left(1+s^{2}\right)^{2} \mu^{2}(1-\mu)^{2}\left(v_{h}-v_{l}\right)^{4}}{64}
$$

This is strictly positive if $0<\mu<1$. Otherwise we have a case of market certainty and in this case hybrid tokens (as well as utility tokens) have no advantage over security tokens. Now compare (19) and (15). The difference between them can be written as

$$
\frac{\left(s^{2}-1\right)^{2}\left(\mu v_{h}^{2}+(1-\mu) v_{l}^{2}\right)^{2}}{64},
$$

which is positive. For the case $s<1$, the firm's profit equals the case when it uses an ICO.

\section{Implications}

Our paper has several implications for an entrepreneurial firm's choice of token design.

Proposition 2 implies that ICO is preferred to STO if the market uncertainty increases or the discount rate decreases. Although this prediction has not been tested directly it is consistent with the spirit of Amsden and Schweizer (2018). They show in their sample of 1009 projects between 2015 and 2017 that ICO success decreases in venture uncertainty and increases in venture quality.

Proposition 4 implies that utility tokens with profit rights dominate security tokens and utility tokens without profit rights. The first part is consistent with Adhami et al. (2018). In a subsample of 253 campaigns, Adhami et al. (2018) document higher returns when tokens allow contributors to access a specific service including profit rights. The second part has not yet been tested. 
Our model is also consistent with the existence of a positive correlation between the platform's quality and the amount raised during an ICO (see, for example, Ante et al. 2018). Indeed, it follows from (A5) and (A6) that the amount raised during the ICO equals:

$$
p_{0}=\frac{\left(8 Q-v^{2}\right) v^{2}}{32}
$$

which means that $p_{0}$ is positively correlated with $Q$.

Finally the model predicts (Proposition 4) that hybrid tokens are more likely to be used when the market scale is sufficiently large.

\section{Model Extensions and Robustness}

\subsection{Cost of Fundraising and Platform Fees}

In our model, the platform fees charged to entrepreneurs for issuing tokens were omitted for simplicity. In this section, we analyze the role of fees that the entrepreneur faces when the firm issues tokens. We assume that in an STO the fee equals $F_{S}$, and in an ICO it is $F_{I} \cdot{ }^{24}$ In fact, the existing evidence shows that STOs are a more expensive way of raising funds compared to ICOs so $\Delta F=F_{S}-F_{I}>0 .{ }^{25}$ When a firm issues utility tokens with profit rights (hybrid tokens) this is still usually classified as an $\mathrm{ICO}^{26}$ so our main result about the optimality of this type of tokens does not change since $\Delta F$ only increases the difference between firm value when it issues hybrid tokens compared to the case with traditional ICO or STO. It is interesting though to compare the case when firms issue utility tokens without profit rights and STO (or to the case when hybrid tokens are classified as an STO and are subject to higher fees). We first compare standard ICO and STO. For the case of market uncertainty without moral hazard, the results do not change since $\Delta F$ only increases the difference between these tokens and STO. Now compare an ICO and STO in the case of moral hazard and/or market uncertainty and moral hazard. Our model predicts that under moral hazard, the firm value under an STO is given by (12) and the firm value under an ICO is given by (9). So the difference equals

$$
\Delta \Pi=\frac{\left(s^{2}-1\right)^{2} v^{4}}{64}-\Delta F .
$$

Proposition 5. (1) For a given value of $s$ and $v$, if $\Delta F$ is sufficiently small than the results are not affected, that is, STO is better than ICO under moral hazard problem; (2) for a given value of s, there exists $v^{*}$ such that STO is better than ICO if and only if $v>v^{*}$; (3) for a given value of $v$, there exists a $U$-shape relationship between s and the firm choice between STO and ICO, that is, STO is better than ICO if $s$ is either very small or very large.

Proof. Follows from (21) and that $\frac{\partial(\Delta \Pi)}{\partial v}>0$ and $\frac{\partial(\Delta \Pi)}{\partial s}=\frac{2 s(s-1)(s+1) v^{4}}{16}$. The latter implies that $\frac{\partial(\Delta \Pi)}{\partial s}$ changes its sign when $s=1$.

In order to see other practical implications of this analysis, we compare the difference in values of firms conducting an ICO and an STO and then compare the difference with empirical evidence. To estimate the value of firm demand we use (7). It implies that $v=2 \sqrt{\left(1+s^{2}\right) \Pi}$. $\Pi$ is estimated from icobench.org. It is usually in the range of $\$ 0.5 \mathrm{mln}$ to $64 \mathrm{mln}$. For $s$ we use the range from 0.1 to $20 .{ }^{27}$ So the range for $v$ is 0.5 to $8 \mathrm{mln}$. 
Table 1. The estimated difference of firm values under ICO and STO under moral hazard (values are in millions). (a) The firm value under ICO; (b) The firm value under STO; (c) The difference between firm value under ICO and STO.

\begin{tabular}{|c|c|c|c|c|c|}
\hline \multicolumn{6}{|c|}{ (a) } \\
\hline \multicolumn{6}{|c|}{ Initial Demand $v$} \\
\hline Market scale $s$ & 0.5 & 1 & 2 & 4 & 8 \\
\hline 20 & 315.63 & 5050.03 & $80,800.50$ & $1,292,808.00$ & $20,684,928.00$ \\
\hline 10 & 20.31 & 325.03 & 5200.50 & $83,208.00$ & $1,331,328.00$ \\
\hline 5 & 1.42 & 22.69 & 363.00 & 5808.00 & $92,928.00$ \\
\hline 1 & 0.01 & 0.19 & 3.00 & 48.00 & 768.00 \\
\hline \multicolumn{6}{|c|}{ (b) } \\
\hline \multicolumn{6}{|c|}{ Initial Demand $v$} \\
\hline Market scale $s$ & 0.5 & 1 & 2 & 4 & 8 \\
\hline 20 & 471.10 & 7537.55 & $120,600.75$ & $1,929,612.00$ & $30,873,792.00$ \\
\hline 10 & 29.89 & 478.17 & 7650.75 & $122,412.00$ & $1,958,592.00$ \\
\hline 5 & 1.98 & 31.69 & 507.00 & 8112.00 & $129,792.00$ \\
\hline 1 & 0.01 & 0.19 & 3.00 & 48.00 & 768.00 \\
\hline \multicolumn{6}{|c|}{ (c) } \\
\hline & \multicolumn{5}{|c|}{ Initial Demand $v$} \\
\hline Market scale $s$ & 0.5 & 1 & 2 & 4 & 8 \\
\hline 20 & 155.47 & 2487.52 & $39,800.25$ & $636,804.00$ & $10,188,864.00$ \\
\hline 10 & 9.57 & 153.14 & 2450.25 & $39,204.00$ & $627,264.00$ \\
\hline 5 & 0.56 & 9.00 & 144.00 & 2304.00 & $36,864.00$ \\
\hline 1 & 0.00 & 0.00 & 0.00 & 00.00 & 4800.00 \\
\hline
\end{tabular}

This implies that the difference between firm value under ICO and STO as predicted by the model is significantly higher than the amount of fees. Indeed, for example, when $s=10$ and $v=2$, it is estimated that about $30 \%$ of the firm value under STO $(2450.25 / 7650.75)$ while the fundraising cost difference is about $1 \% .{ }^{28}$ The comparison of ICO and STO in the case of market uncertainty and moral hazard leads to similar conclusions.

\subsection{Fund Limits}

Here, we assume that the amount of funds that can be raised during a STO or during the issue of utility tokens with profit rights is limited by existing regulations. ${ }^{29}$ Let $L$ denote the maximal amount of funds that can be raised via a STO. Then 2 cases are possible: first the optimal amount of funds raised during STO $\left(L^{*}\right)$ is less than $L$. In this case all results stand because the firm can always select $L^{*}$ and $L$ does not play any role. Secondly, suppose that $L^{*}$ exceeds $L$. Then when considering a STO, the firm should consider an alternative (second-best) strategy.

Proposition 6. (1) For a given value of $s$ and $v$, there exists $L^{* *}<L^{*}$ such that STO is better than ICO under moral hazard if and only if $L>L^{* *}$; (2) for a given value of $L$ and $v$, there exists $s^{*}$ such that STO is better than ICO under moral hazard if and only if $s>s^{*}$; (3) for a given value of $L$ and $s$, there exists $v^{*}$ such that STO is better than ICO under moral hazard if and only if $v<v^{*}$.

Proof. See Appendix A.6.

Under stricter regulation (i.e., smaller L), ICO may become more popular. This framework can help the financial authorities with developing regulation related to STOs including the limits for STO issues. It is also consistent with some empirical evidence that 
STOs are more popular in the US than in Europe. ${ }^{30}$ In the US the maximal possible amount of funds raised during a STO is generally greater than in Europe. ${ }^{31}$

\subsection{Multi-Period Model}

The model can be extended to a multiperiod setting. For example in a model variation with infinite number of periods and discount rate $\delta$ we obtain that in a perfect market the firm value equals $\frac{v^{2}}{4 \delta}$. 32 Under moral hazard, the entrepreneur's profit when the firm issues security tokens is higher than with utility tokens. Under demand uncertainty, the entrepreneur's profit when the firm issues utility tokens is higher than it is when the firm issues security tokens. Under moral hazard and demand uncertainty, the firm's profit if it issues utility tokens equals

$$
\frac{\left(1+4 \delta+\delta^{2}\right)\left(\mu v_{h}^{2}+(1-\mu) v_{l}^{2}\right)^{2}}{32 \delta^{2}(1+\delta)^{2}} .
$$

If the firm issues security tokens, its profit equals

$$
\frac{3\left(\mu v_{h}+(1-\mu) v_{l}\right)^{4}}{64 \delta^{2}}
$$

The likelihood of selecting utility tokens increases (respectively the likelihood of selecting security tokens decreases) when $\mu$ increases from 0 to $\frac{v_{l}}{v_{l}+v_{h}}$ and decreases when $\mu$ increases from $\frac{v_{l}}{v_{l}+v_{h}}$ to 1 ; when $\delta$ increases; for a given value of $v_{l}$ is positively correlated with the difference between $v_{h}$ and $v_{l}$.

With hybrid tokens, under moral hazard and demand uncertainty, the entrepreneur's profit equals:

$$
\frac{3\left(\mu v_{h}^{2}+(1-\mu) v_{l}^{2}\right)^{2}}{64 \delta^{2}}
$$

This is greater than either (22) or (23). First note that (24) is greater than (23). Indeed the difference between them can be written as

$$
\frac{3\left(\mu v_{h}^{2}+(1-\mu) v_{l}^{2}\right)^{2}}{64 \delta^{2}}-\frac{3\left(\mu v_{h}+(1-\mu) v_{l}\right)^{4}}{64 \delta^{2}}=\frac{3 \mu^{2}(1-\mu)^{2}\left(v_{h}-v_{l}\right)^{4}}{64 \delta^{2}} .
$$

Now compare (24) and (22). The difference between them can be written as

$$
\frac{3\left(\mu v_{h}^{2}+(1-\mu) v_{l}^{2}\right)^{2}}{64 \delta^{2}}-\frac{\left(1+4 \delta+\delta^{2}\right)\left(\mu v_{h}^{2}+(1-\mu) v_{l}^{2}\right)^{2}}{32 \delta^{2}(1+\delta)^{2}}=\frac{(1-\delta)^{2}\left(\mu v_{h}^{2}+(1-\mu) v_{l}^{2}\right)^{2}}{64 \delta^{2}(1+\delta)^{2}}
$$

which is positive.

The results are very similar to a 2 period model with only one substantial addition, that the likelihood of selecting utility tokens increases with $\delta$.

\subsection{Different Financing Strategies}

Mixed financing and more types of financing. Unlike capital structure literature, where a debt/equity mix is a very common strategy (as opposed to pure equity or pure debt financing), ${ }^{33}$ simultaneously issuing different types of tokens has not shown to be common. ${ }^{34}$ Nevertheless, if mixed financing is allowed in period 1, most results will stand. In fact, if the firm decides to issue two types of tokens (utility tokens and security tokens) then qualitatively the results are very similar to issuing utility tokens with profit sharing rights. Technically the only difference is that for the equilibrium in operational stage, the calculations are slightly different since with hybrid tokens the buyers of tokens also receive some profit rights that affects their total utility and respectively the equilibrium product prices and so forth. When the firm sells hybrid tokens initially, their value depends on the expected utility that potential buyers expect from the token redemption but also on the expected velocity of tokens. Firstly, delaying consumption affects the present value of the 
token and secondly the buyer can not count on infinite stream of dividends when holding a hybrid token but only on dividends for a number of periods corresponding to the expected velocity of the token (or the time until consumption). When the firm uses two types of tokens separately (utility tokens and security tokens), the calculations are slightly different. The equilibrium in operational stage is similar to the one with utility tokens described previously in, for example, Section 3.1. The velocity of security tokens (or the frequency of selling the token on the secondary market) is irrelevant from the firm's point of view. In terms of tokens' effect on moral hazard issues from the entrepreneur's point of view the results are pretty similar to the basic model qualitatively since in either case the firm benefits from both learning the market demand and improving the participants' incentives.

One can show that in a model with infinite number of periods the firm's profit if it uses a mix of utility and security tokens equals:

$$
\Pi=\frac{\left(3+8 \delta+2 \delta^{2}\right)\left(\mu v_{h}^{2}+(1-\mu) v_{l}^{2}\right)^{2}}{64 \delta^{2}(1+\delta)^{2}} .
$$

This is greater than (24). Indeed the difference between (25) and (24) can be written as $\frac{\delta(\delta-2)\left(\mu v_{h}^{2}+(1-\mu) v_{l}^{2}\right)^{2}}{64 \delta^{2}(1+\delta)^{2}}$ that is negative when $\delta<2$ which is usually the case. From the miner's point of view a mix of utility and security tokens that miners sell to the public in period 1 includes a higher level of expected profit and therefore it increases their incentive compared to hybrid tokens. Indeed security tokens holders expected profit includes an infinite stream of earnings while with hybrid tokens the expected profit depends on expected velocity of tokens (in any case this is less than infinity).

Note that this strategy seems to be becoming quite popular in practice. For example the CEO of Minthealth Samir Damiani stated the following in one of his interviews: "You will absolutely see the rise of the security token. In fact, industry analysts and leaders predict that 25\% (\$20 Trillion) of the existing global equity market of $\$ 80$ Trillion will be security tokens in the next 3 to 5 years, driven primarily by the massive influx of institutional capital. The security token is an incredible tool for companies as they enable stakeholders to participate in the growth of a company and reap the benefits of its success in an SEC compliant manner ... As for the novel dual token structure, we see this as necessary for our company, and likely will become more common in the future. Several industries can benefit from incentivizing consumers. A growing spectrum of industries already have loyalty programs (think Amazon, CVS, Amex etc.). As more companies leverage Blockchain, it is likely the fruits of a dual token structure will become more apparent and widely leveraged." 35 These ideas are very similar to the ones suggested in this paper. In fact, Minthealth has decided to issue two types of tokens. and its motivations are quite similar to the ideas in this article. Dual token structure is definitely an interesting direction for future research. Another promising line is to study debt-based security tokens with profit-sharing rights. A practical example is the case of fundraising for an NBA star Spencer Dinwiddie. ${ }^{36}$

The conclusion that a mix of utility and security tokens is better than hybrid tokens may change if we take into account the fees of tokens issues. Suppose that $F_{B}$ is the fee of issuing utility tokens with profit rights. As we discussed previously, in practice $F_{B}$ seems to be close to $F_{I}$ that implies $F_{I}+F_{S}>F_{B}$. Therefore issuing utility tokens with profit rights would be less expensive for the entrepreneur and respectively more efficient than using a mixed strategy. Hybrid tokens can also be more efficient if one includes in the model a moral hazard issue in operational stage (and not only during platform development stage). This is an interesting area for future research. For example one can consider a model where miners provide production (operational) effort in each period that is hard to control and that affects the products' quality in each period. In this case hybrid tokens might have some advantage compared to a mix strategy because it will provide stronger incentive during operational stages.

Another possible strategy is to sell a hybrid token but then unbundle it. ${ }^{37}$ The idea is to benefit from all advantages of dual token structure as described previously but also to save some cost on fees as was mentioned in the last paragraph. So this strategy can 
be optimal. However more additional considerations should be introduced for this case namely regarding information release (e.g., about firm strategy of unbundling initially issued hybrid tokens) to the potential investors and security token holders and so forth Do they know in advance that the hybrid token will be unbundled in later stage?! If yes, how long it will take to unbundle them? If this information is known then all participants will take it rationally into calculations so the calculations will be similar to the case with dual token structure. If however the participants do not know this information in advance then additional assumptions should be made regarding their risks and expected behavior in the anticipation of this risk and so forth. It is potentially an interesting area for future research that can include some elements of behavioural finance.

Two stages. One can assume that the firm issues tokens in two stages (or staging security and utility token sales separately, etc.). For example in case of utility tokens the firm sells a fraction $t$ of tokens to miners and then $1-t$ to the public. As far as we can see, the results will not change with the introduction of this assumption however if one introduces for example two development periods in the model with two different efforts in each period (a dynamic extension of the model) the results will change at least quantitatively. It is hard to predict the consequences of such a change so it is difficult to judge if it is a promising avenue for future research.

Finally, another line for future research would be to consider a mix of STO and IEO. ${ }^{38}$

\subsection{Legal and Regulatory Issues}

The SEC may consider issuing tokens with profit rights as an STO..$^{39}$ For example, the Kik messenger had a real problem related to this issue and, according to the recent evidence, it has to pay a $5 \$ \mathrm{mln}$ penalty and so on. ${ }^{40}$ In terms of modelling, if hybrid tokens are classified as an STO then the basic model will not change however the model analysis changes when we incorporate token issue fees and fund limits (similar to Sections 7.1 and 7.2 which yield propositions 5 and 6 ). For example, suppose that the firm has to pay a fee $F_{S}$ when issuing hybrid tokens. Then the difference between firm values when it uses hybrid tokens and utility tokens (taking into account (20)) can be written as $\frac{\left(s^{2}-1\right)^{2}\left(\mu v_{h}^{2}+(1-\mu) v_{l}^{2}\right)^{2}}{64}-\Delta F$. The analysis if this difference is very similar to Proposition 5.

\subsection{Cost of Production}

Suppose that the fixed costs of launching production equals $I>0$. The token sale campaign needs to then cover these costs along with the cost of effort by the entrepreneur and the miners. The analysis of this extension is pretty much identical to the main analysis of the model. The only interesting conclusion is that if $I$ is large enough the firm will not be able to use ICO. This is consistent in general with Catalini and Gans (2018) who noted that ICO may not be feasible for a campaign with large number of investments as well as with the spirit of Belleflamme et al. (2014) and Miglo and Miglo (2019) where reward-based crowdfunding can not be used if $I$ is large enough. Similarly one can extend the model by introducing a variable cost of production $c$ per item during operational stage. Main results do not change qualitatively. Note that in this case the firm will have to use a part of tokens sold in the previous period to cover the cost of items.

\subsection{Voting Rights}

One can further extend the model by allowing the firm to develop more than one project in the initial stage with different utilities for the entrepreneur, the miners and the public and let tokenhoders participate in the decision-making process and so forth.

\subsection{Asymmetric Information}

In our paper, we focus on ex-post asymmetric information, that is, an environment where platform quality depends on the effort of its developers. One can consider a model with ex-ante asymmetric information where the entrepreneur initially has some signals 
about its platform and would like to signal it to the market via a token issue. This is an interesting avenue for future analysis but it is beyond the scope of our model. ${ }^{41}$

\subsection{Alternative Ways of Modelling Crowd Behaviour}

In this section, we discuss a different approach to model crowd behavior for example, regarding the assumptions about the market demand for firm's product/services, the expected velocity of tokens and so forth. In the model we assume that token's velocity is 1 year. One of the advantages of this approach is that it simplifies the demand side modelling and helps us focus on market imperfections. Changing the expected velocity of tokens will not change the model results. ${ }^{42}$ An alternative way to approach crowd behavior would be to model individual demands. The latter takes a more industrial organization approach with a focus on individual demands and price discrimination. Our approach is more in the spirit of the financing literature, which is why we adopt a relatively simple demand function. In dynamic monopoly pricing literature this approach is not unusual (see, for example, Demichelis and Tarola 2006). This is also used in capital structure literature that analyzes simultaneously financing and production decisions, which is similar to the spirit of our model (see e.g., Brander and Lewis 1986; Bolton and Scharfstein 1990; Williams 1995). Most of our results (such as Propositions 1, 2 etc.) are intuitively sound and will hold if different demand functions are used. Note that to some extent both approaches are equivalent. Suppose for example, a firm is facing individual customers with different demand functions. A potential consumer's surplus from buying the product is $v-p$, where $p$ is the price and $v$ is the consumer's product valuation. Each consumer only needs one unit of the product/service. The valuation from consuming an extra-unit is zero. Consumers buy/order the product/service as long as they have a non-negative surplus $v-p$, where $p$ is the price. $v$ is uniformly distributed between 0 and $a$. In this setting if the price equals $p$, all consumers with $v$ greater than $p$ will buy the product making the demand $q=a-p$ like in our model.

With regard to hybrid tokens, the same comments apply. Recall that in the model the buyers of hybrid tokens redeem tokens and receive dividends each period. So the market price of tokens reflect the expected amount of dividends as well as their redemption value. Changing the expected velocity of tokens will not change our results qualitatively although quantitatively some formulas will be different. For example a slower velocity of tokens will increase the part of token value related to security token features or dividends since the tokenholders will count on dividends in greater number of periods.

Furthermore, one can consider a significantly different model where, instead of making assumptions about global demand and token expected velocity, one can assume that in each period the usage of hybrid tokens is determined by comparing the redemption value and the value from keeping it. For example, one can assume that there are $N$ potential customers/token buyers in each period and in each period the potential consumers receive a signal about the utility/redemption value of consuming a good in the period which can be $u=v_{h}-p$ with probability $\mu$ and otherwise $u=v_{l}-p, v_{h}>v_{l}$, where $p$ is the token price. In an ideal world when the demand is known and assuming, for example, that consumers are risk-neutral, then if the redemption value is $v_{h}-p$, the firm will charge the price $p=v_{h}$ for the token and sell $N$ tokens which will be exchanged for firm products. In a low-redemption value scenario the price will be $v_{l}$. When information is imperfect, most results hold, for example, utility tokens help the firm learn information about the demand before making production decisions, security tokens improve the incentives of participants and so forth; however, the scenario with hybrid tokens can be slightly different compared to the basic model. Tokenholders have two strategies in each period: redeem their tokens or continue to hold them and receive dividends. In this model some tokens may not necessarily be redeemed in each period. The firm can still receive useful information about demand by observing the token price in the secondary market. In case when the demand is high (i.e., when $v=v_{h}$ ) the analysis is similar to our basic model: the firm will learn the demand from issuing tokens because consumers will be interested in buying the tokens. 
Now consider the case with hybrid tokens when the investors will not redeem tokens when $v=v_{l}$. The firm still learns information by observing the token price on the secondary market. However, tokenholders may not be interested in redeeming their tokens. More formally suppose that the token price is $X$ at the end of period. In the the beginning of the period tokenholders receive a signal about the utility from consuming good. We should assume that at least $v_{h}>X$. Then the token price on the secondary market increase to $v_{h}$. All tokenholders redeem their tokens. Like in the basic model, tokens then are reissued to the new buyers for price $v_{h}$, the volume of production is set $q=N$ and so forth. Now if potential consumers receive a signal that $v=v_{l}$ then two cases can be considered. If $v_{l}>X$ then the same scenario takes place. If $v_{l}<X$ then the secondary market price will not change because nobody will be interested in buying and redeeming tokens. The firm learns that the demand is low. So the firm strategy involving production and sale of goods for tokens may not work in a low demand scenario (because no one will redeem). The firm can cancel the production under low demand scenario while the optimal level of production is $q=N$. So in some cases the hybrid token may not be as efficient as standard utility token. However this holds only for some values of parameters. Consider it more formally. Given the scenario described above we have:

$$
X=\frac{\mu v_{h}+(1-\mu) X}{1+\delta} .
$$

This means that, when the signal is $v=v_{h}$, the secondary market price is $v_{h}$ and otherwise it remains $X$. The equation above reflects the present value of token based on next period value expectations. Then

$$
X=\frac{\mu v_{h}}{\delta+\mu}
$$

and this should be greater than $v_{l}$ and smaller than $v_{h}$. The latter works because $\delta>0$ so this scenario works when $v_{l}$ is sufficiently small.

Secondly, some value loss for the firm is possible even with standard utility tokens. Indeed if the discount factor is not very high, and the tokenholders receive a low redemption value signal, they can wait until future periods when the value will become higher. So in order for the tokenholders to be interested in redeeming their tokens under low-value scenario, the following should hold:

$$
\frac{\mu v_{h}+(1-\mu) v_{l}}{1+\delta}<v_{l}
$$

From (26) and (28), hybrid tokens may not provide an advantage compared to utility tokens in low-demand scenario if

$$
\frac{\mu v_{h}}{\mu+\delta}<v_{l}<\frac{\mu v_{h}+(1-\mu) X}{1+\delta} .
$$

This does not hold. Indeed, substituting (27) into (29), one can see that RHS of (29) is not greater that LHS. It means that in this model, utility tokens may not be used in low-demand scenario for the same range of parameters' values as hybrid tokens. At the same time, hybrid tokens still have an advantage compared to utility tokens in terms of improving the participants incentives and they still have an advantage of learning demand compared to security tokens (at least for a high-demand scenario). So overall the result about optimality of hybrid holds. Furthermore instead of issuing hybrid tokens the firm can use a dual token structure (as described in Section 7.3) with all advantages of learning market demand and improving the participants incentives. As was discussed though it should be checked with regard to the magnitude of fees for issuing different tokens.

In general, this version of the model is an interesting direction for future research. There are advantages and disadvantages of different ways of modelling the demand. We think that using the expected velocity of tokens is not unreasonable with regard to 
utility tokens and hybrid tokens since these are not purely financial assets and have some traditional money features and as was mentioned previously we know many traditional money models that use the concept of expected velocity of money. Using the global demand function may help with focus on the model important features from finance point of view as we discussed previously. In addition note that changes in the total demand for the product may be related to macrofactors, such as overall situation in the economy, the level of competition in the industry and so forth, and these factors may not necessarily be related to the value change from consuming the product that may remain the same. Furthermore, in the model discussed in this section, the concept of optimal production is slightly different compared to the basic model. Indeed, in the absence of global demand function, the firm production is not limited by some demand function in a given period. The above analysis is more applied to situations when the firm has same customers in each period which are ready to consume one unit of firm product in each period. So when the redemption value is low, they will not consume the product and there is a value loss for the firm. However, perhaps another interpretation is possible when the firm receives $N$ new customers each period and those who did not consume the good when the redemption value was low will consume it later along with new customers. So when the demand is low the firm can, for example, still produce goods and store them for future periods and sell them to customers that did not redeem them previously when the redemption value is high and so forth. Miners can be compensated on a loan basis or smth. in periods when the demand is low, or the firm may not produce at all in periods when the redemption value is low but produce more in periods when the redemption value is high. So more scenarios can be considered.

\subsection{Empirical Testing Strategies and Limitations}

Possible tests of our model results and predictions may include direct and indirect tests. The former should be based on connecting firms financing choices with market uncertainty estimations and entrepreneurial effort estimations. Firms financing choices (ICO, STO or hybrid tokens e.g., ICOs with bonuses and also information about the amount of funds raised etc.) can be analyzed using several available data sources eg icobench.org. Market uncertainty measurement is a growing line of research in the existing literature. We mentioned some examples previously. Other papers include Coppejans et al. (2007); Wang et al. (2018) and Amano et al. (2019). Entrepreneurial effort measurements have also been carried out in the existing literature. See, for example, Levy (1990); Ang et al. (2000); Bitler et al. (2005); Basha and Dhavachelvan (2010) and Altaleb and Gravell (2019). Some of these papers are specifically focused on effort measurements in software development sector which are closely related to this paper. Obtaining information about entrepreneurial efforts and market demand is challenging given the limited period of time covered by data for firms issuing tokens and given the absence of systematic information regarding these factors. On the other hand these estimations are challenging even for traditional firms so some proxies and alternative methods can be used similar to the papers mentioned above. Alternatively one can use indirect testing of this paper results by comparing, for example, the average values of firms (or rates of return) that select different token strategies in the spirit of for example, Ante and Fiedler (2019). One would need to find similar firms that conduct ICOs and STOs, identify control groups with similar parameters and quantify factors that led some firms chose ICO, and others chose STO and others chose hybrid tokens. One should take into account that there exist a variety of different types of hybrid tokens and a variety of different ways they pay dividends, bonuses and so forth. One should also correctly estimate the operating performance of these firms given potential difficulties related to innovative features of accounting related to digital assets.

As discussed previously, we leave many interesting topics for future research, such as considering the heterogeneity of consumers' preferences and other modifications of the demand function, and introducing different types of financing strategies and so forth. 


\section{Conclusions}

This article offers a new model of the choice between an ICO and an STO for an innovative firm looking to fund the development of its platform. The existing literature usually focuses on ICOs. Our paper is also one of the first that has a theoretical model of an STO as well as an analysis of utility tokens with profit sharing rights (hybrid tokens). The topic is a quickly growing area among researchers and practitioners. Our model is based on two important features of innovative FinTech firms. First, the presence of moral hazard problems related to the development of platforms. This not only includes entrepreneurs themselves but blockchain participants as well. The quality of a platform is highly uncertain to participants and token design can affect the incentives of the parties involved. Secondly, tokens have secondary markets unlike venture capital investments or crowdfunding. We study how the design of tokens can help the firm learn information about the demand by observing token price. We find that utility tokens are preferred to security tokens when the degree of uncertainty is high. We also find that security tokens may be preferred if the moral hazard problem is important. We then analyze the role of utility tokens with profit sharing rights and other "mixed" strategies of financing and find that these strategies may be more profitable for the entrepreneur compared to utility tokens without profit rights and security tokens. Most of our model's predictions are new (for example, with regard to the effect of different variables such as the discount rates, product demand, the extent of asymmetric information, and so forth, on the choice of financing method) and have not yet been tested but they seem to be consistent to some extent with recent empirical evidence, for example, Adhami et al. (2018).

Funding: This research received no external funding.

Institutional Review Board Statement: Not applicable.

Informed Consent Statement: Not applicable.

Data Availability Statement: All data are openly available.

Acknowledgments: I am grateful to Francis Breedon, Victor Miglo, Jade Mitchell, two anonymous referees and seminar participants at de Montfort University, London South Bank University and Coventry University for helpful comments and editing assistance. I would also like to thank the organizers of Royal Economic Society 2021 and British Accounting and Finance Association 2021 annual meetings for accepting the paper.

Conflicts of Interest: The author declares no conflict of interest.

\section{Appendix A}

Appendix A.1

Proof of Lemma 2. We start with utility tokens.

Consider the operational stage. Similarly to the previous section, we get that the present value of the entrepreneur's profits equals

$$
Q\left(e_{1}, e_{2}\right) \frac{v^{2} s^{2}}{4}
$$

The difference with the previous case is that the quality of the platform was given but here it depends on efforts provided by the entrepreneur and miners. At the beginning of period 1, miners sell their tokens on the secondary market for the value:

$$
p_{1}=Q\left(e_{1}, e_{2}\right) \frac{v^{2}}{4}
$$

At $n=0$, the entrepreneur chooses $e_{1}$ to maximize

$$
Q\left(e_{1}, e_{2}\right) \frac{v^{2} s^{2}}{4}-\frac{e_{1}^{2}}{2}
$$


Taking into account (1), this equals

$$
\frac{\left(e_{1}+e_{2}\right) v^{2} s^{2}}{4}-\frac{e_{1}^{2}}{2}
$$

Optimal $e_{1}$ equals:

$$
e_{1}=\frac{v^{2} s^{2}}{4}
$$

Miners chose $e_{2}$ to maximize their discounted earnings from selling tokens at $t=1$ minus the cost of effort:

$$
p_{1}-\frac{e_{2}^{2}}{2}=Q\left(e_{1}, e_{2}\right) \frac{v^{2}}{4}-\frac{e_{2}^{2}}{2}
$$

Taking into account (1), this equals

$$
\frac{\left(e_{1}+e_{2}\right) v^{2}}{4}-\frac{e_{2}^{2}}{2}
$$

Optimal $e_{2}$ equals:

$$
e_{2}=\frac{v^{2}}{4}
$$

(A2) and (A4) imply

$$
e_{1}+e_{2}=\frac{\left(1+s^{2}\right) v^{2}}{4}
$$

It implies that (A1) equals:

$$
\frac{\left(1+s^{2}\right) s^{2} v^{4}}{16}-\frac{s^{4} v^{4}}{32}=\frac{s^{2}\left(2+s^{2}\right) v^{4}}{32}
$$

and (A3) equals

$$
\frac{\left(1+s^{2}\right) v^{4}}{16}-\frac{v^{4}}{32}=\frac{\left(1+2 s^{2}\right) v^{4}}{32}
$$

When selling tokens, the entrepreneur's total profit is:

$$
p_{0}+\frac{s^{2}\left(2+s^{2}\right) v^{4}}{32}
$$

under the condition that miners' net profit covers the investment cost

$$
p_{0}=\frac{\left(1+2 s^{2}\right) v^{4}}{32}
$$

The entrepreneur's total profit equals then

$$
\Pi=\frac{s^{2}\left(2+s^{2}\right) v^{4}}{32}+\frac{\left(1+2 s^{2}\right) v^{4}}{32}=\frac{\left(s^{4}+4 s^{2}+1\right) v^{4}}{32}
$$

Now consider security tokens. Similar to Section 2, the present value of the entrepreneur's profits from operations equals

$$
Q\left(e_{1}, e_{2}\right)\left(\frac{(1-\alpha) s^{2} v^{2}}{4}+\frac{(1-\alpha) v^{2}}{4}\right)
$$

The entrepreneur chooses $e_{1}$ to maximize

$$
\frac{Q\left(e_{1}, e_{2}\right)\left(1+s^{2}\right)(1-\alpha) v^{2}}{4}-\frac{e_{1}^{2}}{2}
$$


Taking into account (1), this equals

$$
\frac{\left(e_{1}+e_{2}\right)\left(1+s^{2}\right)(1-\alpha) v^{2}}{4}-\frac{e_{1}^{2}}{2}
$$

Optimal $e_{1}$ equals:

$$
e_{1}=\frac{\left(1+s^{2}\right)(1-\alpha) v^{2}}{4}
$$

The miners chose $e_{2}$ to maximize:

$$
Q\left(e_{1}, e_{2}\right)\left(\frac{\alpha s^{2} v^{2}}{4}+\frac{\alpha v^{2}}{4}\right)-\frac{e_{2}^{2}}{2}=\frac{\alpha\left(e_{1}+e_{2}\right)\left(1+s^{2}\right) v^{2}}{4}-\frac{e_{2}^{2}}{2}
$$

The optimal $e_{2}$ equals:

$$
e_{2}=\frac{\left(1+s^{2}\right) \alpha v^{2}}{4}
$$

(A9) and (A11) imply

$$
e_{1}+e_{2}=\frac{\left(1+s^{2}\right) v^{2}}{4}
$$

It implies that (A8) equals:

$$
\frac{\left(1+s^{2}\right)^{2}(1-\alpha) v^{4}}{16}-\frac{\left(1+s^{2}\right)^{2}(1-\alpha)^{2} v^{4}}{32}=\frac{(1-\alpha)(1+\alpha)\left(1+s^{2}\right)^{2} v^{4}}{32}
$$

and (A10) equals

$$
\frac{\left(1+s^{2}\right)^{2} \alpha v^{4}}{16}-\frac{\left(1+s^{2}\right)^{2} \alpha^{2} v^{4}}{32}=\frac{\alpha(2-\alpha)\left(1+s^{2}\right)^{2} v^{4}}{32}
$$

When choosing $\alpha$, the entrepreneur maximizes:

$$
\Pi=p_{0}+\frac{(1-\alpha)(1+\alpha)\left(1+s^{2}\right)^{2} v^{4}}{32}
$$

subject to

$$
p_{0}=\frac{\alpha(2-\alpha)\left(1+s^{2}\right)^{2} v^{4}}{32}
$$

It implies

$$
\Pi=\frac{(1-\alpha)(1+\alpha)\left(1+s^{2}\right)^{2} v^{4}}{32}+\frac{\alpha(2-\alpha)\left(1+s^{2}\right)^{2} v^{4}}{32}=\frac{\left(1+2 \alpha-2 \alpha^{2}\right)\left(1+s^{2}\right)^{2} v^{4}}{32}
$$

Optimal

$$
\alpha=\frac{1}{2}
$$

so the entrepreneur's profit equals

$$
\Pi=\frac{3\left(1+s^{2}\right)^{2} v^{4}}{64}
$$

\section{Appendix A.2}

Proof of Lemma 3. First consider utility tokens. Consider period 2. Product demand is unknown to the entrepreneur ( $v$ equals $v_{h}$ with probability $\mu$ and $v_{l}$ with probability $1-\mu)$. The entrepreneur sells tokens for the price $p_{2}$. After observing $p_{2}$, the entrepreneur determines whether the demand is high or low (the equilibrium $p_{2}=\frac{s^{2} v_{j}^{2}}{4}$ as follows 
from (6) and (A16), $j=l, h$ ). Then the firm determines $q_{2}$. Similarly to Section 3.1, the equilibrium is described by the following conditions:

$$
\begin{gathered}
q_{2}=\frac{s v_{j}}{2} \\
P_{2}=\frac{s v_{j}}{2} \\
T_{2}=\frac{2}{s v_{j}} \\
p_{2}=\Pi_{2}=\frac{s^{2} v_{j}^{2}}{4}
\end{gathered}
$$

The entrepreneur's expected profits equals

$$
\frac{s^{2}\left(\mu v_{h}^{2}+(1-\mu) v_{l}^{2}\right)}{4}
$$

In period 1, miners sell their tokens on the secondary market for the value:

$$
p_{1}=\frac{\mu v_{h}^{2}+(1-\mu) v_{l}^{2}}{4}
$$

When selling tokens, the entrepreneur's total profit is:

$$
\Pi=p_{0}+\frac{s^{2}\left(\mu v_{h}^{2}+(1-\mu) v_{l}^{2}\right)}{4}
$$

subject to

$$
p_{0}=\frac{\mu v_{h}^{2}+(1-\mu) v_{l}^{2}}{4}
$$

It implies

$$
\Pi=\frac{s^{2}\left(\mu v_{h}^{2}+(1-\mu) v_{l}^{2}\right)}{4}+\frac{\mu v_{h}^{2}+(1-\mu) v_{l}^{2}}{4}=\frac{\left(1+s^{2}\right)\left(\mu v_{h}^{2}+(1-\mu) v_{l}^{2}\right)}{4}
$$

Now consider security tokens. In period 2 the firm produces $q_{2}$ items. The price of the item depends on the market demand. If it is $v_{h}$ the price equals $p_{n}=s v_{h}-q_{n}$ and if it is $v_{l}$ the price equals $p_{n}=s v_{l}-q_{n}$. When making its production decision, the firm maximizes its expected profit. The firm's objective function can be written as $\left(\mu s v_{h}+(1-\mu) s v_{l}-q_{n}\right) q_{n}$. Optimal $q$ equals

$$
q_{2}=\frac{s\left(\mu v_{h}+(1-\mu) v_{l}\right)}{2}
$$

Similarly for period 1 we get

$$
q_{1}=\frac{\mu v_{h}+(1-\mu) v_{l}}{2}
$$

and the entrepreneur's profit equals:

$$
\frac{(1-\alpha) s^{2}\left(\mu v_{h}+(1-\mu) v_{l}\right)^{2}}{4}+\frac{(1-\alpha)\left(\mu v_{h}+(1-\mu) v_{l}\right)^{2}}{4}
$$

The miners' profit equals:

$$
\frac{\alpha s^{2}\left(\mu v_{h}+(1-\mu) v_{l}\right)^{2}}{4}+\frac{\alpha\left(\mu v_{h}+(1-\mu) v_{l}\right)^{2}}{4}
$$


When choosing $\alpha$, the entrepreneur maximizes:

$$
\Pi=p_{0}+\frac{(1-\alpha) s^{2}\left(\mu v_{h}+(1-\mu) v_{l}\right)^{2}}{4}+\frac{(1-\alpha)\left(\mu v_{h}+(1-\mu) v_{l}\right)^{2}}{4}
$$

subject to

$$
p_{0}=\frac{\alpha s^{2}\left(\mu v_{h}+(1-\mu) v_{l}\right)^{2}}{4}+\frac{\alpha\left(\mu v_{h}+(1-\mu) v_{l}\right)^{2}}{4}
$$

It implies

$$
\Pi=\frac{s^{2}\left(\mu v_{h}+(1-\mu) v_{l}\right)^{2}}{4}+\frac{\left(\mu v_{h}+(1-\mu) v_{l}\right)^{2}}{4}=\frac{\left(1+s^{2}\right)\left(\mu v_{h}+(1-\mu) v_{l}\right)^{2}}{4}
$$

Appendix A.3

Proof of Proposition 1. Utility tokens. Similarly to Sections 3.1 and 3.2, we get that the present value of the entrepreneur's profits equals

$$
\frac{s^{2}\left(\mu v_{h}^{2}+(1-\mu) v_{l}^{2}\right)}{4}
$$

In period 1, the expected value of tokens sold by miners equals:

$$
p_{1}=\frac{\mu v_{h}^{2}+(1-\mu) v_{l}^{2}}{4}
$$

In period 0 , the entrepreneur choses $e_{1}$ to maximize

$$
\frac{Q\left(e_{1}, e_{2}\right) s^{2}\left(\mu v_{h}^{2}+(1-\mu) v_{l}^{2}\right)}{4}-\frac{e_{1}^{2}}{2}
$$

Taking into account (1), this equals

$$
\frac{\left(e_{1}+e_{2}\right) s^{2}\left(\mu v_{h}^{2}+(1-\mu) v_{l}^{2}\right)}{4}-\frac{e_{1}^{2}}{2}
$$

The optimal $e_{1}$ equals:

$$
e_{1}=\frac{s^{2}\left(\mu v_{h}^{2}+(1-\mu) v_{l}^{2}\right)}{4}
$$

The miners chose $e_{2}$ to maximize:

$$
p_{1}-\frac{e_{2}^{2}}{2}=\frac{\mu v_{h}^{2}+(1-\mu) v_{l}^{2}}{4}-\frac{e_{2}^{2}}{2}
$$

Taking into account (1), this equals

$$
\frac{\left(e_{1}+e_{2}\right)\left(\mu v_{h}^{2}+(1-\mu) v_{l}^{2}\right)}{4}-\frac{e_{2}^{2}}{2}
$$

The optimal $e_{2}$ equals:

$$
e_{2}=\frac{\mu v_{h}^{2}+(1-\mu) v_{l}^{2}}{4}
$$

(A18) and (A20) imply

$$
e_{1}+e_{2}=\frac{\left(1+s^{2}\right)\left(\mu v_{h}^{2}+(1-\mu) v_{l}^{2}\right)}{4}
$$


This implies that (A17) equals:

$$
\frac{s^{2}\left(1+s^{2}\right)\left(\mu v_{h}^{2}+(1-\mu) v_{l}^{2}\right)^{2}}{16}-\frac{s^{4}\left(\mu v_{h}^{2}+(1-\mu) v_{l}^{2}\right)^{2}}{32}=\frac{s^{2}\left(2+s^{2}\right)\left(\mu v_{h}^{2}+(1-\mu) v_{l}^{2}\right)^{2}}{32}
$$

and (A19) equals

$$
\frac{\left(1+s^{2}\right)\left(\mu v_{h}^{2}+(1-\mu) v_{l}^{2}\right)^{2}}{16}-\frac{\left(\mu v_{h}^{2}+(1-\mu) v_{l}^{2}\right)^{2}}{32}=\frac{\left(1+2 s^{2}\right)\left(\mu v_{h}^{2}+(1-\mu) v_{l}^{2}\right)^{2}}{32}
$$

When selling tokens, the entrepreneur's total profit is:

$$
\Pi=p_{0}+\frac{s^{2}\left(2+s^{2}\right)\left(\mu v_{h}^{2}+(1-\mu) v_{l}^{2}\right)^{2}}{32}
$$

subject to

$$
p_{0}=\frac{\left(1+2 s^{2}\right)\left(\mu v_{h}^{2}+(1-\mu) v_{l}^{2}\right)^{2}}{32}
$$

It implies

$$
\begin{gathered}
\Pi=\frac{s^{2}\left(2+s^{2}\right)\left(\mu v_{h}^{2}+(1-\mu) v_{l}^{2}\right)^{2}}{32}+\frac{\left(1+2 s^{2}\right)\left(\mu v_{h}^{2}+(1-\mu) v_{l}^{2}\right)^{2}}{32}= \\
=\frac{\left(s^{4}+4 s^{2}+1\right)\left(\mu v_{h}^{2}+(1-\mu) v_{l}^{2}\right)^{2}}{32}
\end{gathered}
$$

Security tokens. Similarly to Sections 3.1 and 3.2, we get that the present value of the entrepreneur's profits equals

$$
\frac{(1-\alpha) s^{2}\left(\mu v_{h}+(1-\mu) v_{l}\right)^{2}}{4}+\frac{(1-\alpha)\left(\mu v_{h}+(1-\mu) v_{l}\right)^{2}}{4}
$$

In period 1 , the firm choses $e_{1}$ to maximize

$$
\frac{Q\left(e_{1}, e_{2}\right)(1-\alpha)\left(1+s^{2}\right)\left(\mu v_{h}+(1-\mu) v_{l}\right)^{2}}{4}-\frac{e_{1}^{2}}{2}
$$

Taking into account (1), this equals

$$
\frac{\left(e_{1}+e_{2}\right)(1-\alpha)\left(1+s^{2}\right)\left(\mu v_{h}+(1-\mu) v_{l}\right)^{2}}{4}-\frac{e_{1}^{2}}{2}
$$

Optimal $e_{1}$ equals:

$$
e_{1}=\frac{(1-\alpha)\left(1+s^{2}\right)\left(\mu v_{h}+(1-\mu) v_{l}\right)^{2}}{4}
$$

Miners chose $e_{2}$ to maximize:

$$
\frac{\left(e_{1}+e_{2}\right) \alpha\left(1+s^{2}\right)\left(\mu v_{h}+(1-\mu) v_{l}\right)^{2}}{4}-\frac{e_{2}^{2}}{2}
$$

Optimal $e_{2}$ equals:

$$
e_{2}=\frac{\alpha\left(1+s^{2}\right)\left(\mu v_{h}+(1-\mu) v_{l}\right)^{2}}{4}
$$

(A23) and (A25) imply

$$
e_{1}+e_{2}=\frac{\left(1+s^{2}\right)\left(\mu v_{h}+(1-\mu) v_{l}\right)^{2}}{4}
$$

It imply that (A22) equals: 


$$
\begin{aligned}
& \frac{(1-\alpha)\left(1+s^{2}\right)^{2}\left(\mu v_{h}+(1-\mu) v_{l}\right)^{2}}{16}-\frac{(1-\alpha)^{2}\left(1+s^{2}\right)^{2}\left(\mu v_{h}+(1-\mu) v_{l}\right)^{4}}{32}=\frac{(1-\alpha)(1+\alpha)\left(1+s^{2}\right)^{2}\left(\mu v_{h}+(1-\mu) v_{l}\right)^{4}}{32} \\
& \text { and (A24) equals } \\
& \frac{\alpha\left(1+s^{2}\right)^{2}\left(\mu v_{h}+(1-\mu) v_{l}\right)^{4}}{16}-\frac{\alpha^{2}\left(1+s^{2}\right)^{2}\left(\mu v_{h}+(1-\mu) v_{l}\right)^{4}}{32}=\frac{\alpha(2-\alpha)\left(1+s^{2}\right)^{2}\left(\mu v_{h}+(1-\mu) v_{l}\right)^{4}}{32}
\end{aligned}
$$

When choosing $\alpha$, the entrepreneur maximizes:

$$
\Pi=p_{0}+\frac{(1-\alpha)(1+\alpha)\left(1+s^{2}\right)^{2}\left(\mu v_{h}+(1-\mu) v_{l}\right)^{4}}{32}
$$

subject to

$$
p_{0}=\frac{\alpha(2-\alpha)\left(1+s^{2}\right)^{2}\left(\mu v_{h}+(1-\mu) v_{l}\right)^{4}}{32}
$$

It implies

$$
\begin{gathered}
\Pi=\frac{(1-\alpha)(1+\alpha)\left(1+s^{2}\right)^{2}\left(\mu v_{h}+(1-\mu) v_{l}\right)^{4}}{32}+\frac{\alpha(2-\alpha)\left(1+s^{2}\right)^{2}\left(\mu v_{h}+(1-\mu) v_{l}\right)^{4}}{32}= \\
=\frac{\left(1+2 \alpha-2 \alpha^{2}\right)\left(1+s^{2}\right)^{2}\left(\mu v_{h}+(1-\mu) v_{l}\right)^{4}}{32}
\end{gathered}
$$

Optimal

$$
\alpha=\frac{1}{2}
$$

and entrepreneur's profit equals

$$
\Pi=\frac{3\left(1+s^{2}\right)^{2}\left(\mu v_{h}+(1-\mu) v_{l}\right)^{4}}{64}
$$

Appendix A.4

Proof of Lemma 4. We begin the solution by backwards. Consider operational stage. In period 2 there are $q_{2}$ items produced. Tokenholders use their tokens to buy products. Equilibrium is determined by the following conditions: (1) The entrepreneur maximizes his profit, which equals $(1-\alpha) q_{2} T_{2} p_{2} ;(2)$ demand:

$$
q_{2}=s v-P_{2}
$$

where the cost of service for the public $\left(P_{2}\right)$ :

$$
P_{2}=T_{2} p_{2}-\frac{b_{2}}{q_{2}}
$$

Here $b_{n}$ is the total bonus paid by the firm to tokenholders. We assume that each period the firm distributes its profit pro-rata according to number of tokens per holder. ${ }^{43}$ Taking into account (A27) and (A28), we have that the entrepreneur's objective function when the firm selects $q_{2}$ can be written as $(1-\alpha)\left(v-q_{2}\right) q_{2}$. Optimal $q_{2}$ equals

$$
q_{2}=\frac{s v}{2}
$$

The firm's profit (the value of toekns sold) equals:

$$
\left(s v-q_{2}\right) q_{2}=\frac{s^{2} v^{2}}{4}
$$


Note that we have:

$$
\begin{gathered}
P_{2}=\frac{s v}{2} \\
T_{2}=\frac{2}{s v} \\
b_{2}=\alpha \frac{s^{2} v^{2}}{4},
\end{gathered}
$$

also:

$$
p_{2}=\frac{P_{2}+b_{2} / q_{2}}{T_{2}}=\frac{s^{2} v^{2}(1+\alpha)}{4}
$$

The entrepreneur's earnings in period 2 equals $p_{2}-b_{2}=\frac{s^{2} v^{2}}{4}$.

Similarly, in period 1, miners sell their tokens on the secondary market for the value:

$$
p_{1}=\frac{v^{2}(1+\alpha)}{4}
$$

The present value of the entrepreneur's profits equals

$$
\frac{s^{2} v^{2}}{4}-\frac{\alpha v^{2}}{4}
$$

When choosing $\alpha$, the entrepreneur maximizes:

$$
\Pi=p_{0}+\frac{s^{2} v^{2}}{4}-\frac{\alpha v^{2}}{4}
$$

subject to

$$
p_{0}=\frac{v^{2}(1+\alpha)}{4}
$$

It implies

$$
\Pi=\frac{s^{2} v^{2}}{4}+\frac{v^{2}}{4}=\frac{v^{2}\left(s^{2}+1\right)}{4}
$$

Appendix A.5

Proof of Proposition 3. Consider operational stages. Similarly to Lemma 4 we get

$$
\begin{aligned}
q_{2} & =\frac{s v_{j}}{2} \\
P_{2} & =\frac{v_{j}}{2} \\
T_{2} & =\frac{2}{v_{j}}
\end{aligned}
$$

and

$$
p_{2}-b_{2}=\frac{s^{2} v_{j}^{2}}{4}
$$

The present value of the entrepreneur's profits equals

$$
\frac{s^{2}\left(\mu v_{h}^{2}+(1-\mu) v_{l}^{2}\right)}{4}-\frac{\left(\mu v_{h}^{2}+(1-\mu) v_{l}^{2}\right) \alpha}{4}=\frac{\left(\mu v_{h}^{2}+(1-\mu) v_{l}^{2}\right)\left(s^{2}-\alpha\right)}{4}
$$

In period 1, miners sell their tokens on the secondary market for the value:

$$
p_{1}=\frac{\left(\mu v_{h}^{2}+(1-\mu) v_{l}^{2}\right)(1+\alpha)}{4}
$$


In period 0 , the firm choses $e_{1}$ to maximize

$$
\frac{Q\left(e_{1}, e_{2}\right)\left(\mu v_{h}^{2}+(1-\mu) v_{l}^{2}\right)\left(s^{2}-\alpha\right)}{4}-\frac{e_{1}^{2}}{2}
$$

Taking into account (1), this equals

$$
\frac{\left(e_{1}+e_{2}\right)\left(\mu v_{h}^{2}+(1-\mu) v_{l}^{2}\right)\left(s^{2}-\alpha\right)}{4}-\frac{e_{1}^{2}}{2}
$$

Optimal $e_{1}$ equals:

$$
e_{1}=\frac{\left(\mu v_{h}^{2}+(1-\mu) v_{l}^{2}\right)\left(s^{2}-\alpha\right)}{4}
$$

Miners chose $e_{2}$ to maximize:

$$
p_{1}-\frac{e_{2}^{2}}{2}=\frac{\left(\mu v_{h}^{2}+(1-\mu) v_{l}^{2}\right)(1+\alpha)}{4}-\frac{e_{2}^{2}}{2}
$$

Taking into account (1), this equals

$$
\frac{\left(e_{1}+e_{2}\right)\left(\mu v_{h}^{2}+(1-\mu) v_{l}^{2}\right)(1+\alpha)}{4}-\frac{e_{2}^{2}}{2}
$$

Optimal $e_{2}$ equals:

$$
e_{2}=\frac{(1+\alpha)\left(\mu v_{h}^{2}+(1-\mu) v_{l}^{2}\right)}{4}
$$

(A23) and (A25) imply

$$
e_{1}+e_{2}=\frac{\left(1+s^{2}\right)\left(\mu v_{h}^{2}+(1-\mu) v_{l}^{2}\right)}{4}
$$

It implies that (A31) equals:

$$
\begin{gathered}
\frac{\left(s^{2}-\alpha\right)\left(1+s^{2}\right)\left(\mu v_{h}^{2}+(1-\mu) v_{l}^{2}\right)^{2}}{16}-\frac{\left(\mu v_{h}^{2}+(1-\mu) v_{l}^{2}\right)^{2}\left(s^{2}-\alpha\right)^{2}}{32}= \\
=\frac{\left(s^{2}-\alpha\right)\left(2+s^{2}+\alpha\right)\left(\mu v_{h}^{2}+(1-\mu) v_{l}^{2}\right)^{2}}{32}
\end{gathered}
$$

and (A32) equals

$\frac{\left(1+s^{2}\right)(1+\alpha)\left(\mu v_{h}^{2}+(1-\mu) v_{l}^{2}\right)^{2}}{16}-\frac{(1+\alpha)^{2}\left(\mu v_{h}^{2}+(1-\mu) v_{l}^{2}\right)^{2}}{32}=\frac{(1+\alpha)\left(1+2 s^{2}-\alpha\right)\left(\mu v_{h}^{2}+(1-\mu) v_{l}^{2}\right)^{2}}{32}$

When selling tokens, the entrepreneur's total profit is:

$$
\Pi=p_{0}+\frac{\left(s^{2}-\alpha\right)\left(2+s^{2}+\alpha\right)\left(\mu v_{h}^{2}+(1-\mu) v_{l}^{2}\right)^{2}}{32}
$$

subject to

$$
p_{0}=\frac{(1+\alpha)\left(1+2 s^{2}-\alpha\right)\left(\mu v_{h}^{2}+(1-\mu) v_{l}^{2}\right)^{2}}{32}
$$

It implies

$$
\begin{gathered}
\Pi=\frac{\left(s^{2}-\alpha\right)\left(2+s^{2}+\alpha\right)\left(\mu v_{h}^{2}+(1-\mu) v_{l}^{2}\right)^{2}}{32}+\frac{(1+\alpha)\left(1+2 s^{2}-\alpha\right)\left(\mu v_{h}^{2}+(1-\mu) v_{l}^{2}\right)^{2}}{32}= \\
=\frac{\left(1-2 \alpha^{2}-2 \alpha+4 s^{2}+s^{4}+2 \alpha s^{2}\right)\left(\mu v_{h}^{2}+(1-\mu) v_{l}^{2}\right)^{2}}{32}
\end{gathered}
$$


Optimal

$$
\alpha=\frac{s^{2}-1}{2}
$$

and the entrepreneur's profit equals:

$$
\Pi=\frac{3\left(1+s^{2}\right)^{2}\left(\mu v_{h}^{2}+(1-\mu) v_{l}^{2}\right)^{2}}{64}
$$

\section{Appendix A.6}

Proof of Proposition 6. Under STO $L^{*}$ (the case with moral hazard) is given by (A12) and (A14) and equals $\frac{(2-\alpha) \alpha\left(1+s^{2}\right) v^{4}}{32}$ where $\alpha=0.5$. So $L^{*}=\frac{3\left(1+s^{2}\right) v^{4}}{128}$. If $L>L^{*}$, STO dominates ICO under moral hazard. If $L<L^{*}$ then taking into account (A13), the firm should maximize $\Pi(\alpha)=\frac{\left(1+2 \alpha-2 \alpha^{2}\right)\left(1+s^{2}\right)^{2} v^{4}}{32}$ under constraint $p_{0} \leq L$ or $\frac{(2-\alpha) \alpha\left(1+s^{2}\right) v^{4}}{32}<L$. So optimal $\alpha$ solves $-\alpha^{2}\left(1+s^{2}\right) v^{4}-2 \alpha\left(1+s^{2}\right) v^{4}-32 L=0$ and it equals:

$$
\alpha^{*}=\frac{2\left(1+s^{2}\right) v^{4}-\sqrt{4\left(1+s^{2}\right) v^{8}-128 L\left(1+s^{2}\right) v^{4}}}{2\left(1+s^{2}\right) v^{4}}
$$

Then under STO the firm value equals

$$
\Pi\left(\alpha^{*}\right)=\frac{\left(1+2 \alpha^{*}-2\left(\alpha^{*}\right)^{2}\right)\left(1+s^{2}\right)^{2} v^{4}}{32}
$$

If $\Pi\left(\alpha^{*}\right)$ is less than the firm's value under ICO, given by (9) (that is $\left.\frac{\left(s^{4}+4 s^{2}+1\right) v^{4}}{32}\right)$, then ICO is better than STO.

First part Proposition 6 follows from (A34) and (A35). Indeed it holds if $L>L^{*}$ as was argued previously. Consider $L<L^{*}$. $\alpha^{*}$ increases in $L$ and so the maximal value of $\alpha^{*}$ equals $1 / 2$ when $L=L^{*}$. As follows from (A35), $\Pi\left(\alpha^{*}\right)$ increases in $\alpha^{*}$ when $\alpha^{*}<1 / 2$. The rest of Proposition 6 can be proven similarly.

\section{Notes}

1 In contrast to utility tokens, security tokens are regulated. The legal structures continue to evolve. In the US, for example, the Securities and Exchange Commission (SEC) applies the Howey test to determine whether an asset qualifies as a security. Essentially, investments are considered securities if money is invested, the investment is expected to yield a profit, the money is invested in a common enterprise and any profit comes from the efforts of a promoter or third party SEC vs. Howey (1946).

2 Ante and Fiedler (2019).

3 Blockstate Global STO Study (2019).

4 The empirical literature includes, among others, Boreiko and Risteski (2020); Masiak et al. (2020); Momtaz (2020) and Huang et al. (2020) See, for example, Kher et al. (2020) for a review.

5 We use the terms utility tokens with profit rights and hybrid tokens throughout the paper interchangeably. Note that the term hybrid tokens is quite popular in media articles and reports (see e.g., https:/ / www.lawandblockchain.eu/ the-case-for-hybrid-tokens/, accessed on 19 April 2021; https:/ / medium.com/@calevanscrypto/the-hybrid-tokenoffering-95615239d639, accessed on 19 May 2021).

6 See, for example, https://www.businesswire.com/news/home/20190711005651/en/, accessed on 19 April 2021.

7 See, for example, OECD (2019). For related research regarding security issues with smart tokens see, for example, Hancke et al. (2009).

8 See, for example, Das (2019).

9 For a good discussion of economics of tokens including different examples of connections between the effort of independent miners and the success of the firm see, for example, Holden and Malani (2019) and Chod et al. (2019). They also discuss different reasons for why tokens are often used for compensating miners' efforts and different types of relationship between the platform and miners (including e.g., PoW-"proof of work" and PoS-"proof of 
stakes") and so forth. In particular they explain the advantages of PoS used by many firms such as Filecoin and so forth. Under PoS a platform requires miners to use tokens and so forth. Miners must stake some tokens and if they are not successful they cannot use these tokens, so miners have an incentive to work efficiently.

10 Protocol Labs, Inc. (2017).

11 See http:/ / www.bcointalk.com/investing/Block-state-CEO-Paul-Claudius-in-an-Interview-In-Switzerland-it-ismuch-easier-to-STO-than-they-have-been-in-Germany-h1524.html, accessed on 19 April 2021.

12 See, for example, Oxera (2015) and Nadaulda et al. (2019). Regarding feedback feature of crowdsourcing see a review by Zhang et al. (2019). See Turulja and Bajgorić (2018) on the links between knowledge acquisition and innovation. See also Ballestar (2021).

13 Kukoin (2019), see also https:// www.youtube.com/watch?v=pK1Piw943yI\&t=34s, accessed on 19 April 2021.

14 See also Mella-Barral and Sabourian (2018).

15 In Section 7, we discuss the model's assumptions including the ways of modelling moral hazard, demand for the product and so forth.

16 In Section 7, we discuss more possible strategies of financing.

17 They can be paid for with fiat money and a cryptocurrencies such as Bitcoin, Ether and so forth.

We do not consider the case where the firm issues tokens and runs out of business with cash. This type of managerial operational moral hazard is considered in for example, some papers on crowdfunding (see e.g., Strausz 2017) that is similar to the spirit of ICOs to some extent. In our case it would not be an optimal strategy for the firm since it will not get any cash from selling tokens in future periods (the market participants would not buy tokens from the firm that "cheated" on them previously). An interpretation would be a tit-for-tat repeated game equilibrium failure (see e.g., Hargreaves-Heap and Varoufakis 2004). This is clearly not optimal. Any production decision that does not maximize the number of tokens received from selling goods (and respectively the value of tokens received) is not optimal either. One can show that any $q$ that is different from $v / 2$ leads to a smaller value of tokens sold in long-term equilibrium using Equations (2)-(6).

19 Similar ideas have been discussed in the literature on reward-based crowdfunding where the participants should be incentivized to participate in pre-sales, for example, the pre-sale price should not exceed future spot price. For a discussion see, for example, Belleflamme et al. (2014); Miglo (2019) or Miglo (2020b).

20 Recall that the token velocity is equal to one period. This is chosen for simplicity. Qualitatively, the results will not change if a different velocity is chosen. For the effect of velocity on ICOs, see, for example, Holden and Malani (2019).

21 Note that in monetary economics, for example, it is common to use the expected velocity of money (see e.g., Lucas 1988; Ireland 1996; Alvarez et al. 2001; Cochrane 2005). As was mentioned previously the velocity of tokens was studied in Holden and Malani (2019).

22 In particular we discuss a model variation that does not have a global demand and does not have an expected velocity of tokens and where instead the redemption of value of tokens is introduced and where each tokenholder has two strategies in each period (redeem tokens or continue to hold them).

23 Since in a digital economy the firm inflows includes both tokens and cash and since the regulation is not yet perfectly developed there exists a variety of different interpretations of a firm's profit (see e.g., Boyanov 2019). One we consider here is consistent with the spirit of financing literature although different ways of modelling are possible, for example, tokenholders' profit can be calculated as a fraction of money received from reselling tokens (this is not exactly in the spirit of traditional literature since money received from selling shares during IPO for example are not considered the firm profit although it is a form of firm capital). Note also that the firm can transfer cash between periods with no costs (e.g., invests in bonds or borrow funds etc.). So this mitigates the problem of potential accounting differences between firm cash and firm profit in each period. Note that none of these assumptions are crucial. The results hold under different ways of modelling.

24 Most charge lump sum, see, for example, https://medium.com/@jaronlukas/the-leading-security-token-issuance-platformsa-summary-comparison-ac8d42290f98, accessed on 19 April 2021, https:/ /www.investopedia.com/news/how-much-does-itcost-list-ico-token/, accessed on 19 May 2021, http:/ / chainplus.one/blog/step-by-step-how-to-launch-an-sto/\#: \protect \char1 26\relax:text=Simply $\% 20$,speaking $\% 2 C \% 20$ the $\% 20$ cost $\% 20$ for, to $\% 20$ costs $\% 20$ being $\% 20$ significantly $\%$ 20higher, accessed on 19 April 2021.

25 See, for example, https://www.pwc.ch/en/publications/2019/ch-PwC-Strategy\&-ICO-Report-Summer-2019.pdf, accessed on 19 April 2021. https:/ / www.quora.com/Does-the-setup-for-an-STO-cost-higher-than-an-ICO-If-so-why-arepeople-gravitating-to-security-token-offerings, accessed on 19 May 2021.

26 See, for example, https:/ / dailyfintech.com/2019/08/27/hybrid-security-tokens-what-are-they-and-what-are-theynot/, accessed on 19 April 2021. 
27 In a model with infinite number of periods that we discuss later, the firm value is about $\frac{v^{2}}{4 \delta}$ where $\delta$ is the discount rate. So $\frac{1}{\delta}$ determines the difference between firm total earnings and its earnings in the first period. $1+s^{2}$ has a similar interpetation in our basic model (see e.g., Lemma 1). So, if we take the range of values for $\delta$ between $0.25 \%$ and $100 \%$, it gives us approximately the range of values for $s$ used in Table 1.

28 For example, an ICO cost is estimated as about \$500,000 (see e.g., https: / / www.bitcoinmarketjournal.com/launchingan-ico/, accessed on 19 April 2021) and an STO cost (in general it is similar to ICO but includes the registration fees and cost) is estimated as about \$1,000,000 (see e.g., https:/ / www.finyear.com/Cost-Benefits-of-STO-vs-PrivatePlacement_a40021.html, accessed on 19 April 2021. The difference equals $\$ 500,000$ which is about $1.2 \%$ of the STO value.

29 See e.g., https: / / www.taipeitimes.com/News/biz/archives/2019/06/28/2003717700, accessed on 19 April 2021.

30 See, for example, PwC/Strategy\& (2020).

31 See e.g., https:// otonomos.com/2020/01/security-token-regulations-demystified/, accessed on 19 April 2021.

32 Proofs are available upon demand. See also Miglo (2019).

33 For a review of capital structure literature see, among others, Harris and Raviv (1991) or Miglo (2011). For a traditional analysis of the capital structure of internet companies see, for example, Miglo et al. (2014). For an alternative model of mixed token finance see Gan et al. (2021).

See https:/ /blog.polymath.network/minthealth-and-polymath-bring-the-first-healthcare-security-token-to-revolutionize-healthcarea36884f17e4e, accessed on 19 April 2021; https:/ / hackernoon.com/how-to-do-an-sto-an-exclusive-interview-with-the-founder-ofminthealth-ba24be0c6025, accessed on 19 May 2021.

36 See https://www.coindesk.com/nba-players-contract-tokenization-plan-can-move-forward-reports, accessed on 19 May 2021.

37 For similar ideas see e.g., https:/ / multicoin.capital/2019/05/24/the-unbundling-of-ethereum/, accessed on 19 May 2021, https: / / www.linkedin.com/pulse/unbundling-rebundling-payments-aaron-mcpherson, accessed on 19 May 2021.

38 IEO (initial exchange offering) is a new form of fundraising where tokens are offered through exchanges. For more details see, for example, Miglo (2020a). See also https:/ / hackernoon.com/can-the-combination-of-sto-ieo-becomethe-new-step-in-crowdfunding-evolution-y943m42rj accessed on 19 April 2021.

39 Kik-messenger, https:/ / www.coindesk.com/the-8-biggest-bombshells-from-the-secs-kik-ico-lawsuit, accessed on 19 May 2021.

40 See e.g., https://www.jdsupra.com/legalnews/kik-in-the-butt-court-decision-against-52403/, accessed on 19 May 2021.

41 See, for example, Belleflamme et al. (2014), Miglo (2019) and Miglo (2020c) for the analysis of the role of asymmetric information in crowdfunding.

42 Holden and Malani (2019) analyze the role of the velocity of tokens.

43 Recall that the token velocity is one year. In Section 6 we dsicuss different extensions related to this assumtpion.

\section{References}

Adhami, Saman, Giancarlo Giudici, and Stefano Martinazzi. 2018. Why do businesses go crypto? An empirical analysis of Initial Coin Offerings. Journal of Economics and Business 100: 64-75.

Alchian, Armen, and Harold Demsetz. 1972. Production, Information Costs, and Economic Organization. American Economic Review 62: 777-95.

Altaleb, Abdullah, and Andrew Gravell. 2019. An Empirical Investigation of Effort Estimation in Mobile Apps Using Agile Development Process. Journal of Software 14: 356-69.

Alvarez, Fernando, Robert E. Lucas, and Warren E. Weber. 2001. Interest Rates and Inflation. American Economic Review 91: $219-25$.

Amano, Tomomichi, Andrew Rhodes, and Stephan Seiler. 2019. Large-Scale Demand Estimation with Search Data. Working Paper. Available online: https:/ / papers.ssrn.com/sol3/papers.cfm?abstract_id=3214812 (accessed on 19 May 2021).

Amsden, Ryan, and Denis Schweizer. 2018. Are Blockchain Crowdsales the New "Gold Rush"? Success Determinants of Initial Coin Offerings. Working Paper. Available online: https:/ / papers.ssrn.com/sol3/papers.cfm?abstract_id=3163849 (accessed on 12 December 2018).

Ang, James S., Rebel Cole, and James Wuh Lin. 2000. Agency Costs and Ownership Structure. The Journal of Finance 55: 81-106.

Ante, Lennart, and Ingo Fiedler. 2019. Cheap Signals in Security Token Offerings (STOs). BRL Working Paper Series No. 1. Available online: https:/ / papers.ssrn.com/sol3/papers.cfm?abstract_id=3356303 (accessed on 1 February 2020).

Ante, Lennart, Philipp Sandner, and Ingo Fiedler. 2018. Blockchain-based ICOs: Pure Hype or the Dawn of a New Era of Startup Financing? Journal of Risk and Financial Management 11: 80.

Bakos, Yannis, and Hanna Halaburda. 2018. The Role of Cryptographic Tokens and ICOs in Fostering Platform Adoption. Available online: https:/ / papers.ssrn.com/sol3/papers.cfm?abstract_id=3207777 (accessed on 19 May 2021).

Ballestar, María T. 2021. Segmenting the Future of E-Commerce, One Step at a Time. Journal of Theoretical and Applied Electronic Commerce Research 16: i-iii. 
Basha, Saleem, and Ponnurangam Dhavachelvan. 2010. Analysis of Empirical Software Effort Estimation Models. International Journal of Computer Science and Information Security 7: 68-77.

Bellavitis, Cristiano, Christian Fisch, and Johan Wiklund. 2020. A comprehensive review of the global development of initial coin offerings (ICOs) and their regulation. Journal of Business Venturing Insights 15: e00213. doi:10.1016/j.jbvi.2020.e00213

Belleflamme, Paul, Thomas Lambertz, and Armin Schwienbacher. 2014. Crowdfunding: Tapping the Right Crowd. Journal of Business Venturing: Entrepreneurship, Entrepreneurial Finance, Innovation and Regional Development 29: 585-609.

Bitler, Marianne, Tobias J. Moskowitz, and Annette Vissing-Jørgensen. 2005. Testing Agency Theory with Entrepreneur Effort and Wealth. The Journal of Finance 60: 539-576.

Blockstate Global STO Study. 2019. Available online: https:/ /blockstate.com/global-sto-study-en/ (accessed on 1 February 2020).

Bolton, Patrick, and David Scharfstein. 1990. A Theory of Predation Based on Agency Problems in Financial Contracting. American Economic Review 80: 93-106.

Boreiko, Dmitri, and Dimche Risteski. 2020. Serial and large investors in initial coin offerings. Small Business Economics. Forthcoming. Boyanov, Borislav. 2019. Approaches for Accounting and Financial Reporting of Initial Coin Offering (ICO). Paper presented at 15th International Conference of ASECU, Sofia, Bulgaria, September 26-27, pp. 74-83. Available online: https://www.researchgate. net/publication/340933834_Approaches_for_Accounting_and_Financial_Reporting_of_Initial_Coin_Offering_ICO (accessed on 1 February 2020).

Brander, James, and Tracy R. Lewis. 1986. Oligopoly and Financial Structure: The Limited Liability Effect. American Economic Review 76: 956-70.

Canidio, Andrea. 2018. Financial Incentives for Open Source Development: The Case of Blockchain. MPRA Working Paper. Available online: https:/ / mpra.ub.uni-muenchen.de/103804/1/MPRA_paper_103804.pdf (accessed on 19 April 2020).

Catalini, Christian, and Joshua S. Gans. 2018. Initial Coin Offerings and the Value of Crypto Tokens. NBER Working Paper 24418. Available online: https:/ /www.nber.org/papers/w24418 (accessed on 19 April 2021).

Chemla, Gilles, and Katrin Tinn. 2019. Learning Through Crowdfunding. Management Science 66: $1783-801$.

Chen, Long, Lin William Cong, and Yizhou Xiao. 2021. A Brief Introduction to Blockchain Economics. Singapore: World Scientific Publishing Company, chp. 1. doi:10.1142/9789811220470_0001.

Chod, Jiri, and Evgeny Lyandres. 2019. A Theory of ICOs: Diversification, Agency, and Information Asymmetry. Working Paper. Available online: https:/ / ssrn.com/abstract=3159528 (accessed on 19 April 2020).

Chod, Jiri, Nikolaos Trichakis, and Alex Yang. 2019. Platform Tokenization: Financing, Governance, and Moral Hazard. Working Paper. Available online: http:/ / www.econ.ntu.edu.tw/uploads/asset/data/607fc66648b8a10278021ae7/HKBU_1100429.pdf (accessed on 19 April 2021).

Cochrane, John H. 2005. Money as Stock. Journal of Monetary Economics 52: 501-28.

Coinschedule. 2018. Cryptocurrency ICO Stats. Available online: https://www.coinschedule.com/stats.html (accessed on 9 December 2018).

Cong, Lin William, Ye Li, and Neng Wang. 2018. Tokenomics: Dynamic Adoption and Valuation. Working Paper. Available online: https:/ / bfi.uchicago.edu/working-paper/tokenomics-dynamic-adoption-and-valuation/ (accessed on 19 April 2020).

Coppejans, Mark, Donna Gilleskie, Holger Sieg, and Koleman Strumpf. 2007. Consumer Demand Under Price Uncertainty: Empirical Evidence from the Market for Cigarettes. The Review of Economics and Statistics 89: 510-21.

Das, Sanjiv R. 2019. The Future of FinTech. Financial Management 48: 981-1007.

Demichelis, Stefano, and Ornella Tarola. 2006. Capacity expansion and dynamic monopoly pricing. Research in Economics 60: 169-78.

Ellman, Matthew, and Sjaak Hurkens. 2017. A Theory of Crowdfunding a Mechanism Design Approach with Demand Uncertainty and Moral Hazard: Comment. Available online: http:/ / www.iae.csic.es/investigatorsMaterial/a1812160140sp40258.pdf (accessed on 19 April 2020).

Gan, Rowena, Gerry Tsoukalas, and Serguei Netessine. 2020. Initial Coin Offerings, Speculation, and Asset Tokenization. Management Science 67: 914-31. doi:10.1287/mnsc.2020.3796

Gan, Rowena, Gerry Tsoukalas, and Serguei Netessine. 2021. To Infinity and Beyond: Financing Platforms with Uncapped Crypto Tokens. SMU Cox School of Business Research Paper No. 21-03. Available online: https://papers.ssrn.com/sol3/papers.cfm? abstract_id=3776411 (accessed on 19 April 2021).

Garicano, Luis, Adam Meirowitz, and Luis Rayo. 2017. Information Sharing and Moral Hazard in Teams. Working Paper. Available online: https://d30i16bbj53pdg.cloudfront.net/wp-content/uploads/2017/12/14_Rayo_Information-Sharing-andMoral-Hazard-in-Teams.pdf (accessed on 19 April 2020).

Garratt, Rodney, and Maarten R. C. van Oordt. 2019. Entrepreneurial Incentives and the Role of Initial Coin Offerings. Staff Working Paper. Ottawa: Bank of Canada. Available online: https://www.bankofcanada.ca/2019/05/staff-working-paper-2019-18/ (accessed on 19 May 2020).

Graham, John R., and Campbell Harvey. 2001. The theory and practice of corporate finance: Evidence from the field. Journal of Financial Economics 60: 187-243.

Gryglewicz, Sebastian, Simon Mayer, and Erwan Morellec. 2020. Optimal Financing with Tokens. Working Paper. Available online: https:/ / personal.eur.nl/gryglewicz/files/tokens.pdf (accessed on 19 May 2020).

Hall, Bronwyn H. 2009. The Financing of Innovative Firms. EIB Papers 14: 8-29. 
Hancke, Gerhard, Keith E. Mayes, and Konstantinos Markantonakis. 2009. Confidence in smart token proximity: Relay attacks revisited. Computers \& Security 28: 615-27.

Hargreaves-Heap, Shaun P., and Yanis Varoufakis. 2004. Game Theory: A Critical Text. London: Routledge. ISBN 978-0-415-25094-8.

Harris, Milton, and Artur Raviv. 1991. The Theory of Capital Structure. Journal of Finance 46: 297-355.

Holden, Richard, and A. Malani. 2019. The ICO Paradox, Transaction Costs, Token Velocity, and Token Value. NBER Working Papers 26265. Cambridge: NEBR.

Holmström, Bengt. 1982. Moral Hazard in Teams. Bell Journal of Economics 13: 324-40.

Howell, Sabrina T., Marina Niessner, and David Yermack. 2018. Initial Coin Offerings: Financing Growth with Cryptocurrency Token Sales. NBER Working Papers 24774. Cambridge: National Bureau of Economic Research, Inc.

Huang, Winifred, Michele Meoli, and Silvio Vismara. 2020. The geography of initial coin offerings. Small Business Economics 55: 77-102.

Ireland, Peter N. 1996. The Role of Countercyclical Monetary Policy. Journal of Political Economy 104: 704-23.

Jankowski, Jarosław, Przemysław Kazienkoa, Jarosław Watróbski, Anna Lewandowska, Paweł Ziemba, and Magdalena Zioło. 2016. Fuzzy multi-objective modeling of effectiveness and user experience in online advertising. Expert Systems with Applications 65: 315-31.

Jensen, Michael C., and William H. Meckling. 1976. Theory of the Firm: Managerial Behavior, Agency Costs and Ownership Structure. Journal of Financial Economics 3: 305-60.

Kher, Romi, Siri Terjesen, and Chen Liu. 2020. Blockchain, Bitcoin, and ICOs: A review and research agenda. Small Business Economics. Forthcoming.

Kukoin. 2019. Michael AMA @ TRON Community: Exchanges Are Naturally for Staking Services. Available online: https://www. kucoin.com/news/en-michael-ama-tron-community-exchanges-are-naturally-for-staking-services (accessed on 19 May 2020).

Lambert, Thomas, Daniel Liebau, and Peter Roosenboom. 2020. Security Token Offerings. Working Paper. Available online: https:/ / www.researchgate.net/publication/342419787_Security_Token_Offerings (accessed on 19 May 2020).

Lee, Jeongmin, and Christine A. Parlour. 2020. Consumers as Financiers: Crowdfunding, Initial Coin Offerings and Consumer Surplus. Working Paper. Available online: https:/ / www.chapman.edu/research/institutes-and-centers/economic-science-institute/ files/ifree-papers-and-photos/parlour-lee-consumers-as-financiers-2019.pdf (accessed on 19 May 2020).

Levy, Zeeva. 1990. Estimating the Effort in the Early Stages of Software Development. Ph.D. thesis, London School of Economics and Political Science, London, UK.

Li, Jiasun, and William Mann. 2018. Digital Tokens and Platform Building. Working Paper. Available online: https://pdfs. semanticscholar.org/309e/f98741d5da2003df8317fd605e1ac83d6fb9.pdf (accessed on 19 May 2020).

Li, Li, and Zixuan Wang. 2019. How does capital structure change product-market competitiveness? Evidence from Chinese firms. PLoS ONE 14: e0210618.

Lucas, Robert E., Jr. 1988. Money Demand in the United States: A Quantitative Review. Carnegie-Rochester Conference Series on Public Policy 29: 169-72.

Masiak, Christian, Joern H. Block, Tobias Masiak, Matthias Neuenkirch, and Katja N. Pielen. 2020. Initial coin offerings (ICOs): Market cycles and relationship with bitcoin and ether. Small Business Economics 55: 1113-130.

Mella-Barral, Pierre, and Hamid Sabourian. 2018. Sequel Firm Creation and Moral Hazard in Teams. Working Paper. Available online: https://www.law.northwestern.edu/research-faculty/clbe/events/innovation/documents/mella-barral_seqone_03.pdf (accessed on 19 May 2020).

Miglo, Anton. 2011. Trade-off, Pecking order, Signalling, and Market Timing Models. In Capital Structure and Corporate Financing Decisions: Theory, Evidence, and Practice. Edited by Gerald S. Martin and H. Kent Baker, Hoboken: John Wiley \& Sons.

Miglo, Anton. 2019. STO vs. ICO: A Theory of Token Issues Under Moral Hazard and Demand Uncertainty. Working Paper. Available online: https: / / ssrn.com/abstract=3449980 (accessed on 19 April 2020).

Miglo, Anton. 2020. Choice between IEO and ICO: Speed vs. Liquidity vs. Risk. Working Paper. Available online: https://ssrn.com/ abstract $=3561439$ (accessed on 19 April 2020).

Miglo, Anton. 2020. Crowdfunding in a Competitve Environment. Journal of Risk and Financial Management. Forthcoming.

Miglo, Anton. 2020. Crowdfunding under Market Feedback, Asymmetric Information and Overconfident Entrepreneur. Entrepreneurship Research Journal. Forthcoming.

Miglo, Anton. 2020. ICO vs. Equity Financing under Imperfect, Complex and Asymmetric Information. Working Paper. Available online: https: / / ssrn.com/abstract=3539017 (accessed on 19 May 2020).

Miglo, Anton. 2021. Theories of Crowdfundign and Token Issues: A Review. Submitted.

Miglo, Anton, and Victor Miglo. 2019. Market Imperfections and Crowdfunding. Small Business Economics 53: 51-79.

Miglo, Anton, Zhenting Lee, and Shuting Liang. 2014. Capital Structure of Internet Companies: Case Study. Journal of Internet Commerce 13: 253-81.

Modigliani, Franco, and Merton Miller. 1958. The Cost of Capital, Corporation Finance and the Theory of Investment. American Economic Review 48: 261-97.

Momtaz, Paul P. 2020. Initial Coin Offerings, Asymmetric Information, and Loyal CEOs. Small Business Economics. Forthcoming.

Myers, Stewart C., and Nicholas S. Majluf. 1984. Corporate financing and investment decisions when firms have information that investors do not have. Journal of Financial Economics 13: 187-222. 
Nadaulda, Taylor D., Berk A. Sensoy, Keith Vorkink, and Michael S. Weisbach. 2019. The liquidity cost of private equity investments: Evidence from secondary market transactions. Journal of Financial Economics 132: 158-81.

OECD. 2019. Initial Coin Offerings (ICOs) for SME Financing. Available online: https://www.oecd.org/finance/initial-coin-offeringsforsmefinancing.htm (accessed on 19 April 2020).

Oxera. 2015. Crowdfunding from An Investor Perspective. Prepared for the European Commission Financial Services User Group. Available online: https:/ / ec.europa.eu/info/sites/info/files/file_import/160503-study-crowdfunding-investor-perspective_ en_0.pdf (accessed on 1 February 2020).

Protocol Labs, Inc. 2017. Filecoin Primer. Available online: https:/ /ipfs.io/ipfs/QmWimYyZHzChb35EYojGduWHBdhf9SD5NHqf8 MjZ4n3Qrr/Filecoin-Primer.7-25.pdf (accessed on 1 February 2020).

PwC/Strategy\&. 2020. 6th ICO/STO Report. Available online: https://www.pwc.ch/en/publications/2020/Strategy\&_ICO_STO_ Study_Version_Spring_2020.pdf (accessed on 19 May 2020).

Schwienbacher, Armin. 2018. Entrepreneurial Risk-taking in Crowdfunding Campaigns. Small Business Economics 51: 843-59.

SEC vs. Howey. 1946. SEC v. WJ Howey Co., 328 U.S. 293, 66 S.Ct. 1100, 90 L. Ed. 1244. Available online: https://www.law.cornell. edu/supremecourt/text/328/293 (accessed on 19 April 2020).

Stiglitz, Josef, and Andrew Weiss. 1981. Credit rationing in markets with imperfect information. American Economic Review 73: $393-409$.

Strausz, Roland. 2017. Crowdfunding, Demand Uncertainty, and Moral Hazard-A Mechanism Design Approach. American Economic Review 107: 1430-476.

Turulja, Lejla, and Nijaz Bajgorić. 2018. Knowledge Acquisition, Knowledge Application, and Innovation Towards the Ability to Adapt to Change. International Journal of Knowledge Management 14: 1-15.

Wang, Luyao, Hong Fan, and Tianren Gong. 2018. The Consumer Demand Estimating and Purchasing Strategies Optimizing of FMCG Retailers Based on Geographic Methods. Sustainability 10: 466. doi:10.3390/su10020466

Watróbski, Jarosław, Jarosław Jankowski, and Paweł Ziemba. 2016. Multistage Performance Modelling in Digital Marketing Management. Economics and Sociology 9: 101-25.

Williams, Joseph T. 1995. Financial and Industrial Structure with Agency. The Review of Financial Studies 8: 431-75.

Wilson, Karen E. 2015. Policy Lessons from Financing Innovative Firms. OECD Science, Technology and Industry Policy Papers No. 24. Paris: OECD Publishing. Available online: http:/ /dx.doi.org/10.1787/5js03z8zrh9p-en (accessed on 1 February 2020).

Zhang, Xuefeng, Mingshuang Chen, and Guanqun Ji. 2019. Factors influencing the crowd participation in knowledge-intensive crowdsourcing. Paper presented at 4th International Conference on Crowd Science and Engineering, Jinan, China, October 18-21. doi:10.1145/3371238.3371268 